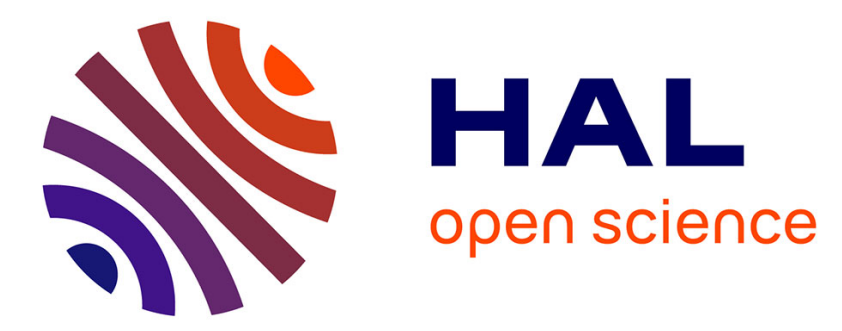

\title{
Temperature-dependent VNIR spectroscopy of hydrated Mg-sulfates
}

\author{
S. de Angelis, C. Carli, F. Tosi, P. Beck, B Schmitt, G. Piccioni, M.C. C de \\ Sanctis, F. Capaccioni, T. Di Iorio, Sylvain Philippe
}

\section{- To cite this version:}

S. de Angelis, C. Carli, F. Tosi, P. Beck, B Schmitt, et al.. Temperature-dependent VNIR spectroscopy of hydrated Mg-sulfates. Icarus, 2017, 281, pp.444-458. 10.1016/j.icarus.2016.07.022 . hal-03103065

\section{HAL Id: hal-03103065 https://hal.science/hal-03103065}

Submitted on 8 Jan 2021

HAL is a multi-disciplinary open access archive for the deposit and dissemination of scientific research documents, whether they are published or not. The documents may come from teaching and research institutions in France or abroad, or from public or private research centers.
L'archive ouverte pluridisciplinaire HAL, est destinée au dépôt et à la diffusion de documents scientifiques de niveau recherche, publiés ou non, émanant des établissements d'enseignement et de recherche français ou étrangers, des laboratoires publics ou privés. 


\section{Temperature-dependent VNIR spectroscopy of hydrated Mg-sulfates}

${ }^{1}$ Istituto di Astrofisica e Planetologia Spaziali, INAF-IAPS, Via del Fosso del Cavaliere 100, I-00133 Roma, Italy

${ }^{2}$ Institut de Planétologie et d'Astrophysique de Grenoble (IPAG), 414 Rue de la Piscine, F-38400 St-Martin d'Hères (France), France

${ }^{3}$ ENEA Centro Ricerche Casaccia (ENEA SSPT-PROTER-OAC), Via Anguillarese 301, I-00123 Roma, Italy

\section{Abstract}

We investigate two poly-hydrated magnesium sulfates, hexahydrite $\left(\mathrm{MgSO}_{4} \cdot 6 \mathrm{H}_{2} \mathrm{O}\right)$ and epsomite $\left(\mathrm{MgSO}_{4} \cdot 7 \mathrm{H}_{2} \mathrm{O}\right)$, in the visible and infrared (VNIR) spectral range $0.5 \div 4.0 \mu \mathrm{m}$, as particulate for three different grain size ranges: 20-50 $\mu \mathrm{m}, 75-100 \mu \mathrm{m}$ and 125-150 $\mu \mathrm{m}$. All samples were measured in the $93 \mathrm{~K}$ to $298 \mathrm{~K}$ temperature range. The spectra of these hydrated salts are characterized by strong $\mathrm{OH}$ absorption bands in the 1.0-1.5 $\mu \mathrm{m}$ region, and by $\mathrm{H}_{2} \mathrm{O}$ absorption bands near 2 and $3 \mu \mathrm{m}$. Other weak features show up at low temperatures near $1.75 \mu \mathrm{m}$ (in both hexahydrite and epsomite) and $2.2 \mu \mathrm{m}$ (only in hexahydrite). The spectral behavior of the absorption bands of these two minerals has been analyzed as a function of both grain size and temperature, deriving trends related to specific spectral parameters such as band center, band depth, band area, and band width. Hydrated minerals, in particular mono- and poly-hydrated sulfates, are present in planetary objects such as Mars and the icy Galilean satellites. Safe detection of these minerals shall rely on detailed laboratory investigation of these materials in different environmental conditions. Hence an accurate spectral analysis of such minerals as a function of temperature is key to better understand and constrain future observations.

Keywords. Mars. Europe. Sulfates. VNIR spectroscopy. JUICE.

\section{Introduction}

Sulfate minerals in different states of hydration are present in the Solar System. Combined in situ measurements, remote-sensing observations and laboratory investigations carried out in recent years have allowed to detect hydrated sulfates on Mars (Brueckner 2004; Gendrin et al., 2005; 
Chevrier and Mathè, 2006; Murchie et al., 2009; Ehlmann et al., 2014) and on icy satellites like Europa and Ganymede (McCord et al., 1999; McCord et al., 2001; Dalton et al., 2005). Nathues et al. (2015) suggested the presence of hydrated sulfates on the dwarf planet Ceres based on Dawn observations.

Sulfates on Earth can originate from different geologic processes, such as: (i) precipitation due to water evaporation in lakes or sabkhas environments, (ii) interaction rocks-acidic groundwater in hydrothermal environments, and (iii) aqueous alteration of volcanic products (Warren, 2006, 2010). On the Earth, magnesium sulfate has three stable hydration states: kieserite $\left(\mathrm{MgSO}_{4} \cdot \mathrm{H}_{2} \mathrm{O}\right)$, hexahydrite $\left(\mathrm{MgSO}_{4} \cdot 6 \mathrm{H}_{2} \mathrm{O}\right)$ and epsomite $\left(\mathrm{MgSO}_{4} \cdot 7 \mathrm{H}_{2} \mathrm{O}\right)$. It has been shown (Vaniman et al., 2004) that kieserite is easily hydrated at high relative humidity conditions $(>55 \% \mathrm{RH})$ and converted in hexahydrite and epsomite, although the reverse transformation upon desiccation is unlikely. Moreover hexahydrite and epsomite tend to transform to an amorphous phase when subject to rapid dehydration and pressure reduction (Vaniman et al., 2004; Wang et al., 2006; Cloutis et al., 2007), and tend to dehydrate when exposed to UV radiation (Cloutis et al., 2007).

Mars. According to Feldman et al. (2004), who studied the distribution of subsurface epithermal neutrons, various hydrated states of magnesium salts could be present at equatorial latitudes on Mars. Brueckner (2004) described layered outcrops in Meridiani Crater containing sulfate as cementation agent. Based on OMEGA (Mars Express; Bibring et al., 2004) observations, Gendrin et al. (2005) proposed magnesium mono-hydrated (kieserite) and poly-hydrated (epsomite) sulfates to occur, together with calcium sulfates, in outcrops in several Martian layered terrains, located in Valles Marineris, Margaritifer Sinus and Terra Meridiani (Chevrier and Mathè, 2006). However, the same OMEGA data could be well fitted with iron poly-hydrated sulfates. Generally kieserite and poly-hydrated sulfates occur as light deposits in these layered terrains. Kieserite and polyhydrated sulfate phases have also been suggested by the observations of CRISM (Mars Reconnaissance Orbiter; Murchie et al., 2007) in Meridiani Planum and Valles Marineris layered deposits (Murchie et al., 2009; Weitz et al., 2015) and in paleolakes (Wray et al., 2009). However it is still poorly understood if hydrated phases are stable under all Martian conditions and during daytime and seasonal cycles (Roach et al., 2009). Mars Science Laboratory instruments onboard Curiosity rover have detected mainly hydrated calcium-sulfates at Yellowknife Bay (Rice et al., 2013; Nachon et al., 2013).

Icy Galilean satellites. The presence of hydrated salts of magnesium on the surface of Europa has been suggested on the basis of Galileo/NIMS spectra (McCord et al., 1998; McCord et al., 1999; McCord et al., 2010). McCord et al. (1998) argued that the presence of hexahydrite and epsomite on Europa (as well as of other sulfates) could be explained by hydrothermal activity related to the subsurface ocean and consequent material upwelling. NIMS spectra of Europa's reddish plains are thought to resemble those of hydrated magnesium sulfates with a high number of water molecules (Dalton et al., 2005), although it has been pointed out that Europa's non-icy terrains are likely composed of mixtures of different types of sulfates (McCord et al., 1999). Best fits for nonicy terrains on Europa are indeed provided by mixtures of hexahydrite, bloedite $\left(\mathrm{Na}_{2} \mathrm{Mg}\left(\mathrm{SO}_{4}\right)_{2}\right.$. $\left.4 \mathrm{H}_{2} \mathrm{O}\right)$, mirabilite $\left(\mathrm{Na}_{2} \mathrm{SO}_{4} \cdot 10 \mathrm{H}_{2} \mathrm{O}\right)$, and sulfuric acid hydrate $\left(\mathrm{H}_{2} \mathrm{SO}_{4} \cdot \mathrm{nH}_{2} \mathrm{O}\right)$ (Dalton, 2007). Carlson 
et al. (2009) alternatively suggested that the surface of Europa is mainly constituted by polyhydrated sulfuric acids, produced after irradiation of $\mathrm{SO}_{2}$ in water ice.

Meteorites. Hydrated Mg-sulfates (epsomite) have also been identified in the matrices of carbonaceous chondrites (Burgess et al., 1991) after stepped combustion experiments. Other authors report various types of sulfates also in veins and grains in carbonaceous chondrites (Fredriksson and Kerridge, 1988; Brearley and Jones, 1998). Hutchison (2006) reports the presence of epsomite particularly in veins and matrices of $\mathrm{Cl}$ carbonaceous chondrites, although some authors (Gounelle and Zolensky, 2001) assess that some of the sulfates in $\mathrm{Cl} 1$ chondrites could have formed by terrestrial alteration.

Laboratory investigations. Laboratory studies have shown that the main diagnostic absorption features in VNIR spectra of hydrated sulfates do not undergo dramatic changes in position when exposed to simulated Martian conditions (Cloutis et al., 2007), while major changes in bands' shapes and parameters occur at cryogenic temperatures (Dalton et al., 2005). Band parameters of hexahydrite have been shown to slightly change depending on ambient conditions (UV radiation, $\mathrm{CO}_{2}$ atmosphere and pressure) (Craig et al., 2006). A lot of work has been done to better understand the stability of hydrated Mg-sulfates in various physical conditions (Vaniman et al., 2004; Wang et al., 2006; Cloutis et al., 2007), to study the cycles of hydration-dehydration between the various phases $\mathrm{MgSO}_{4} \cdot \mathrm{nH}_{2} \mathrm{O}$ (Chou and Seal II, 2007), and to characterize the VNIR spectral behavior of large suites of sulfates with the goal of separating them (Crowley, 1991; Van Keulen et al., 2000; Cloutis et al., 2006). Reflectance spectra of several hydrated sulfates in the near infrared range have been studied at room and cryogenic temperatures (Dalton et al., 2005). In particular hexahydrite and epsomite have been measured at $300 \mathrm{~K}$ and $100 \div 120 \mathrm{~K}$ in the spectral range $0.3-2.5 \mu \mathrm{m}$ by Dalton et al. (2005; 2012); hexahydrite spectra at 300K and 77K have been measured by McCord et al. (1999) in the range $0.9 \div 2.5 \mu \mathrm{m}$. Dalton et al. (2011) investigated hexahydrite spectra in the range $0.5-2.5 \mu \mathrm{m}$, in the temperature range $150-300 \mathrm{~K}$. Here we discuss the spectral behavior, in the extended visible and infrared range (0.5-4.0 $\mu \mathrm{m})$, of hexahydrite and epsomite, considering a wide range of temperatures $(93 \div 298 \mathrm{~K})$. Measurements have been performed at $8 \div 10$ temperature steps in the above range and with three different grain sizes, in order to document the evolution of band parameters with temperature. From the summary hitherto presented, the investigation of hydrate sulfates in a spectral range comparable to remote sensing observation carried onboard ongoing and future interplanetary space missions is key to enforce the interpretation of those data. The presence of hydrated minerals, in particular monoand poly-hydrated sulfates, in Solar System objects such as Mars and the icy Galilean satellites, requires detailed laboratory investigation of these materials in different environmental conditions. Hence a detailed spectral analysis of such minerals as a function of temperature is key to better understand and constrain future observations 


\subsection{Experimental setup}

Measurements have been performed with the Spectro-Gonio-Radiometer facility (Brissaud et al, 2004) at the Institut de Planétologie et d'Astrophysique of Grenoble (IPAG). The instrument is a bidirectional VIS-NIR reflectance spectrometer; two detectors have been used to cover the 0.5-4.0 $\mu \mathrm{m}$ spectral range: a CCD in the 0.5-1.0 $\mu \mathrm{m}$ range and an IR detector in the 1.0-4.0 $\mu \mathrm{m}$ range. $\mathrm{A}$ monochromator was used as light dispersion element. Spectralon and Infragold (Labsphere (C) were used as commercial reference targets with an absolute calibration of the BRDF of Spectralon (Bonnefoy 2001). All spectra have been acquired with an illumination angle $i=20^{\circ}$ and an emission angle $e=20^{\circ}$. The spectral resolution used in this setup is: $5 \mathrm{~nm}$ for $\lambda=0.45-0.7 \mu \mathrm{m}, 12 \mathrm{~nm}$ for $\lambda=0.7-1.0 \mu \mathrm{m}, 24 \mathrm{~nm}$ for $\lambda=1.0-2.0 \mu \mathrm{m}$ and $48 \mathrm{~nm}$ for $\lambda=2.0-4.5 \mu \mathrm{m}$.

Measurements were carried out within the CARBONIR environmental chamber coupled with the spectro-gonio-radiometer (Grisolle 2013, Grisolle et al., 2014; Beck et al., 2015). This chamber is made of a large closed isothermal copper cell (diameter of $8 \mathrm{~cm}$ ) inserted in a stainless steel chamber. The copper cell is cooled with a He-cryostat and optical access is permitted through sapphire windows. This setup enables measurement of reflectance spectra at temperatures down to $50 \mathrm{~K}$. In order to ensure efficient thermal coupling of the sample, a few mbar (monitored during the experiment) of dry air were kept in the cell. The cell temperature is monitored during the experiment and the error on sample temperature is estimated to be of the order of $1 \mathrm{~K}$.

\subsection{Samples}

Two sulfate samples have been analyzed. Hexahydrite $\left(\mathrm{MgSO}_{4} \cdot 6 \mathrm{H}_{2} \mathrm{O}\right)$, which is hexa-hydrated magnesium sulfate, and epsomite $\left(\mathrm{MgSO}_{4} \cdot 7 \mathrm{H}_{2} \mathrm{O}\right)$, which is epta-hydrated magnesium sulfate. Each sample has been grinded from coarser grains and dry-sieved by shaking in three different grain sizes: 20-50 $\mu \mathrm{m}, 75-100 \mu \mathrm{m}$ and 125-150 $\mu \mathrm{m}$. The grain sizes have been chosen in order to avoid overlapping between ranges, so as to minimize particles contamination among the dimensional classes.

\subsection{Reflectance measurements}

Spectra have been acquired for each grain size at different temperatures (Figs. 1,2,3). The whole temperature range covers $93 \mathrm{~K} \div 298 \mathrm{~K}$. Measurements have been performed at steps of $10 \div 15 \mathrm{~K}$ in the low temperature range, and at steps of $20 \div 25 \mathrm{~K}$ in the high temperature range, for a total of $8 \div 10$ steps on average for each grain size. All samples have been analyzed starting at the lowest temperature $\left(T_{0}=93 \mathrm{~K}\right)$ and then acquiring subsequent spectra during the rise of $T$ up to $298 \mathrm{~K}$.

All the band parameters have been computed after removing the spectral continuum (Figs. $4 a, b, c)$ : for each band a straight line has been drawn between the band edges, by intersecting the 
visually identified maxima of both band extremes, and then removed by dividing the spectrum by this line. The band center is determined by applying a second-order polynomial fit around the band minimum, and taking the resulting minimum of the fit as the band center value. The depth is computed, following Clark and Roush (1984), as $D=\left(R_{C}-R_{B}\right) / R_{C}$, where $R_{B}$ and $R_{C}$ are the reflectance of the band and the spectral continuum at the band center, respectively. The width has been computed by intersecting the continuum-removed band with a horizontal line passing through half depth. In the case of multi-peak bands (Fig. 4b), the continuum line for background removal is drawn between the edges of the whole band, and each single peak is fitted with second-order polynomials. The 3- $\mu \mathrm{m}$ feature, as schematized in Fig. 4c, is very asymmetric, and is indeed due to the overlapping of two absorptions, a narrow one centered at $2.7 \mu \mathrm{m}(\mathrm{O}-\mathrm{H}$ stretching) and a much broader one centered near $3 \mu \mathrm{m}$ (overtone of $\mathrm{H}-\mathrm{O}-\mathrm{H}$ bending occurring near $6 \mu \mathrm{m}$ ) [Clark et al., 1990]. We decided to focus on the 3- $\mu \mathrm{m}$ absorption and modeled the minimum with a secondorder polynomial, because of high instrumental noise around $2.7 \mu \mathrm{m}$. It should be noted that, in principle, the whole band could be fitted by the sum of two Gaussians, with higher spectral resolution and higher signal-to-noise data.

\section{Results: spectral parameters analysis}

\subsection{Spectral variability}

Measured spectra are shown in Fig. 1 (hexahydrite) and Fig. 2 (epsomite). The spectra of these hydrated minerals are very similar in the overall profile, although several subtle differences arise when looking at the absorption bands in detail. A test was performed by measuring a given sample (hexahydrite, 125-150 $\mu \mathrm{m}$ ) both during the temperature-increasing and the decreasing phase: no major changes have been observed neither in the spectral profiles nor in the band positions (Fig. 3). Spectra of both hexahydrite and epsomite are characterized by several absorption bands in the range $1.0 \div 3.7 \mu \mathrm{m}$. The main features are centered at 1.0, 1.2, 1.35, 1.5, 1.9, 2.2, 2.5, 2.7 and 3.0 $\mu \mathrm{m}$. Essentially all these features are due to transitions in $\mathrm{O}-\mathrm{H}$ groups and in $\mathrm{H}_{2} \mathrm{O}$ molecules. The bands at 1.0,1.2, 1.35, 1.5 are overtones and combinations of the stretching fundamental transition in $\mathrm{OH}$ groups present in the crystal lattice, occurring near $2.75 \mu \mathrm{m}$ (Hunt, 1977; Clark et al., 1990; Dalton et al., 2005).

The features near 1.9 and $3.0 \mu \mathrm{m}$ are due to $\mathrm{O}-\mathrm{H}$ stretching and $\mathrm{H}-\mathrm{O}-\mathrm{H}$ bending vibrations in the $\mathrm{H}_{2} \mathrm{O}$ molecule. The fundamental modes of these transitions occur near 2.9, 3 and $6 \mu \mathrm{m}$, and overtones and combinations are observable in the VNIR range near 0.94, 1.14, 1.38, 1.45 and 1.9 $\mu \mathrm{m}$ (Hunt, 1977; Clark et al., 1990). Association of $\mathrm{SO}_{4}{ }^{2-}$ groups and $\mathrm{H}_{2} \mathrm{O}$ molecules could be responsible of the features appearing at $2.2 \mu \mathrm{m}$ (in hexahydrite) and $2.5 \mu \mathrm{m}$ (in both samples) (Gendrin et al., 2005; Cloutis et al., 2006) rather than metal-OH bond vibrations (Hunt, 1977; Clark et al., 1990; Clark, 1999). Bending and stretching vibrations in S-O groups could be observed here, because overtones of fundamental vibration modes occurring in the 8-24 $\mu \mathrm{m}$ region are expected 

in the 4-5 $\mu \mathrm{m}$ region and in the 2.1-2.7 $\mu \mathrm{m}$ region, which falls within our range of sensitivity (Cloutis et al., 2006).

According to Cloutis et al. (2006), the absorption feature at $2.55 \mu \mathrm{m}$ could be related to $\mathrm{OH} / \mathrm{H}_{2} \mathrm{O}$ content. The $\mathrm{OH}$ band in the 1.5- $\mu \mathrm{m}$ region is broad and has edges at 1.3 and $1.8 \mu \mathrm{m}$ approximately. In the case of hexahydrite $\left(6 \cdot \mathrm{H}_{2} \mathrm{O}\right)$, the fine structure of the band is constitued by a triplet that becomes more and more defined as temperature decreases. The first two features of the triplet occur at 1.47 and $1.55 \mu \mathrm{m}$; the third is weak (with a width of about $20 \mathrm{~nm}$ ) and is visible only at very low temperatures, therefore it has not been considered here. At higher temperatures only the band centered at $1.47 \mu \mathrm{m}$ is evident. In the case of epsomite $\left(7 \cdot \mathrm{H}_{2} \mathrm{O}\right)$, this band is constitued by a doublet; the two absorptions centered at 1.5 and $1.62 \mu \mathrm{m}$ become more and more resolved as temperature drops down, and the feature at $1.62 \mu \mathrm{m}$ tends to have a nearly flat base; a higher spectral resolution would be needed to properly discern the band structure. The water band at 3 micron is very broad and almost saturates the absorption; its wings extend up to $3.7 \mu \mathrm{m}$ in the infrared region. The long-wavelength edge of the band tends to become unrecognizable especially for coarser grain sizes and at higher temperatures, as shown for example by the spectrum of hexahydrite $125-150 \mu \mathrm{m}$ at $298 \mathrm{~K}$ (Fig. 1). In spectra of epsomite (Fig. 2) the longwavelength edge of the 3-micron band completely disappears for grain sizes 75-100 and 125-150 $\mu \mathrm{m}$, at temperatures higher than $203 \mathrm{~K}$.

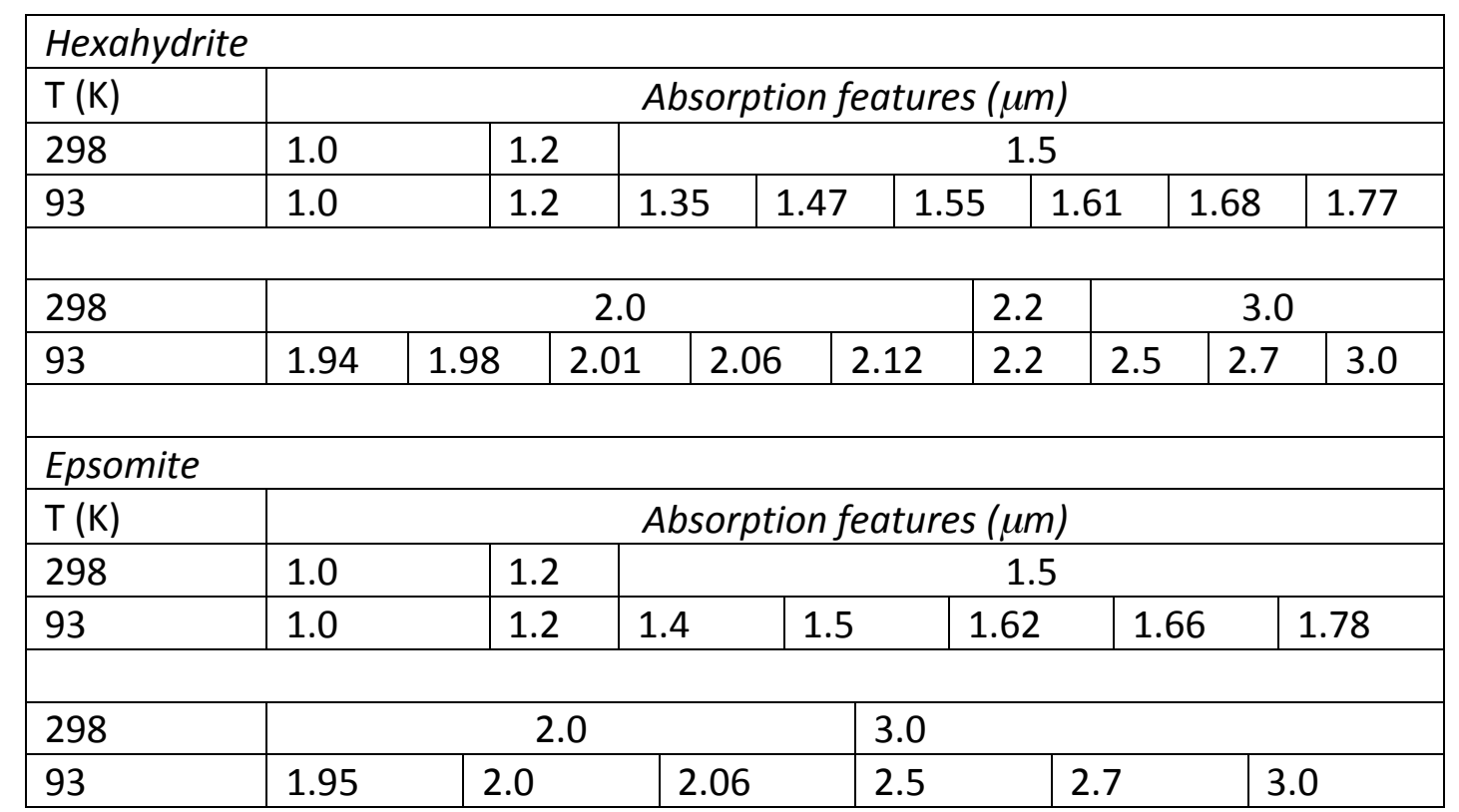



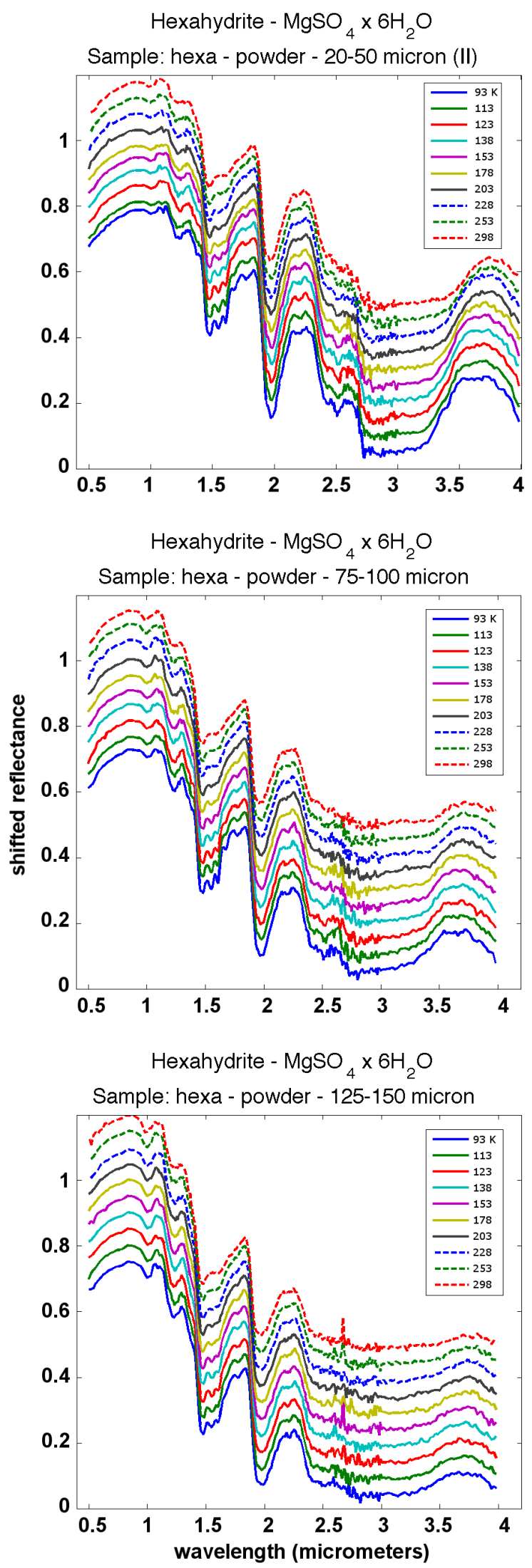

208 Fig.1. Spectra of hexahydrite at different temperatures, in the range $93 \div 298 \mathrm{~K}$. Top: grain size $20-50 \mu \mathrm{m}$.

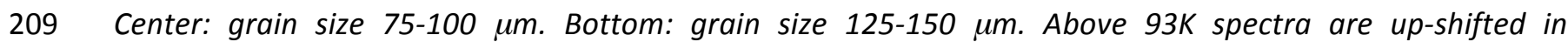
210 reflectance by 0.05 for clarity. 


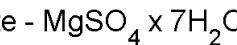

Sample: hepta - powder - 20-50 micron

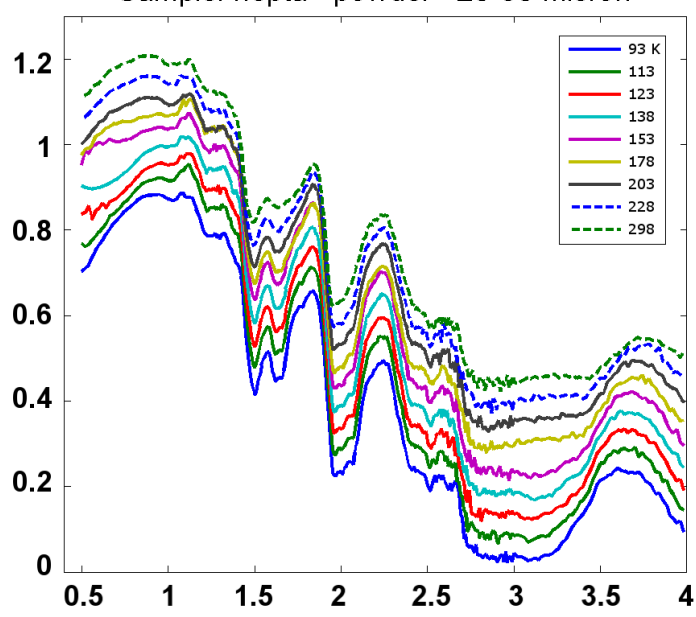

Epsomite - $\mathrm{MgSO}_{4} \times 7 \mathrm{H}_{2} \mathrm{O}$

Sample: hepta - powder - 75-100 micron

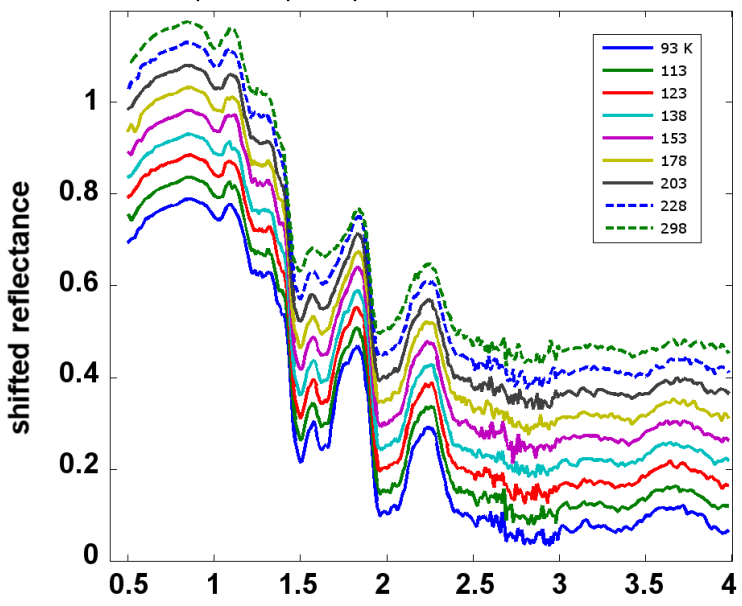

Epsomite - $\mathrm{MgSO}_{4} \times 7 \mathrm{H}_{2} \mathrm{O}$

Sample: hepta - powder - 125-150 micron

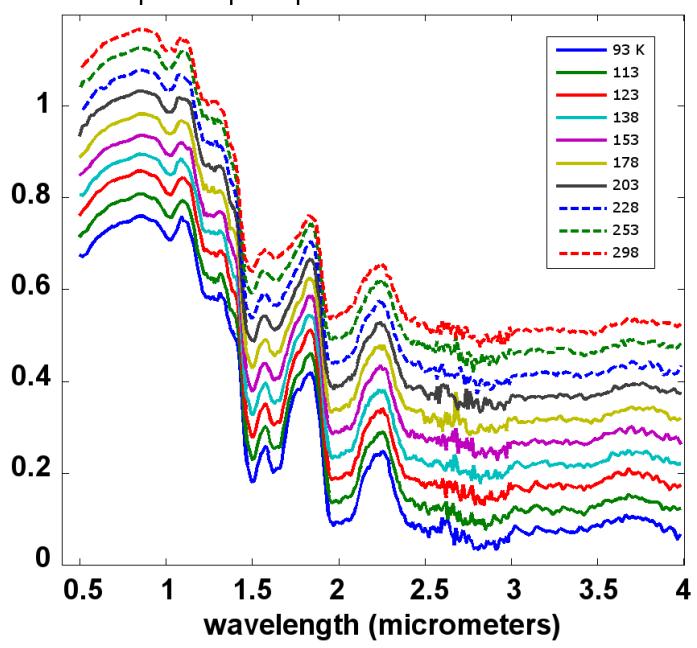

212 Fig.2. Spectra of epsomite at different temperatures, in the range $93 \div 298 \mathrm{~K}$. Top: grain size $20-50 \mu \mathrm{m}$.

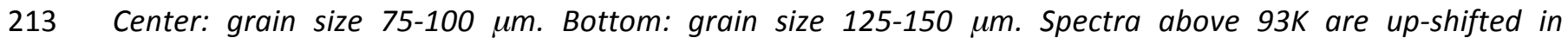
214 reflectance of 0.05 for clarity. 


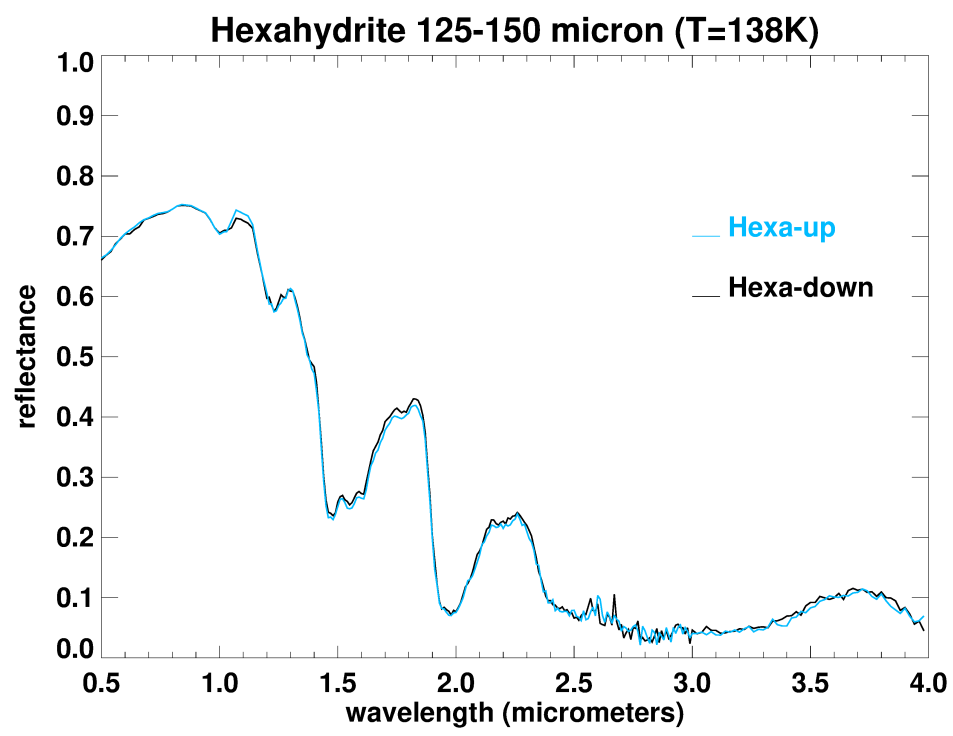

Fig.3. Spectra of hexahydrite (125-150 um) at $T=138 \mathrm{~K}$. The cyan ("up") spectrum has been acquired during the temperature-increase phase of measurements; the black ("down") spectrum has been acquired during the temperature-decrease phase. The spectral profiles do not show variations.

\subsection{Spectral parameters analysis}

Different absorption bands have been analyzed for each spectrum of the two samples, in the entire range of explored temperatures (Fig. 4a). Band parameters such as position, area, depth and width have been determined (Fig. 4b,c). Thus for each sample and each grain size, the band parameters have been studied as a function of temperature. Depending on the particular analyzed absorption feature, for some values of temperature it was not possible to retrieve some of the parameters. All parameters were computed after removal of the spectral continuum, as described in Section 2.3. 

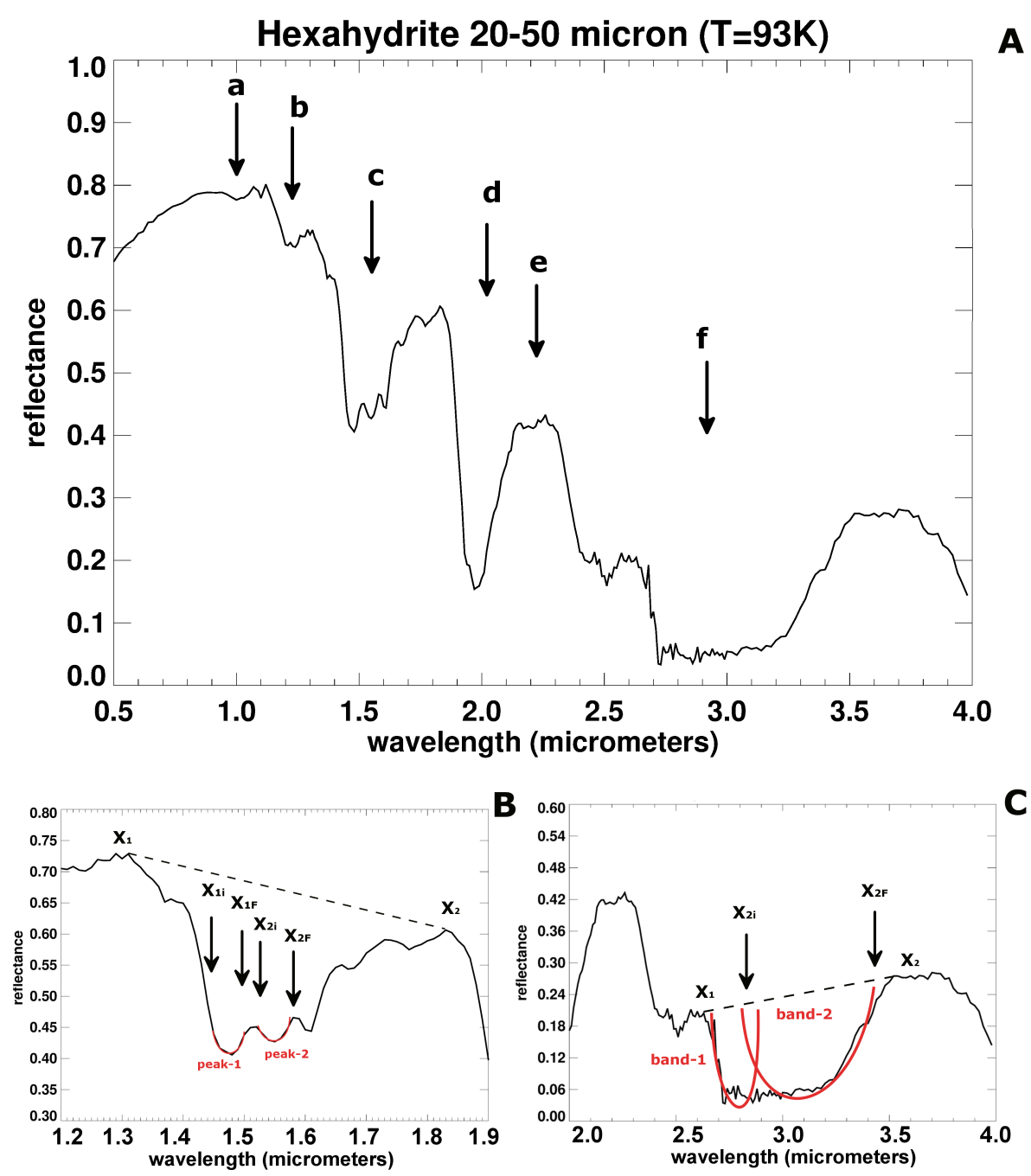

Fig.4. A: absorption bands analyzed in the spectra of the two samples. Band a: 1 um. Band b: $1.2 \mu \mathrm{m}$. Band c: $1.5 \mu \mathrm{m}$. Band d: $2 \mu \mathrm{m}$. Band e: $2.2 \mu \mathrm{m}$. Band f: $3 \mu \mathrm{m}$. B: method of band fitting for multi-peak bands. In the case of the broad 1.5- $\mu \mathrm{m}$ feature, the continuum baseline has been drawn between the points $X_{1}, X_{2}$. After continuum removal by division, the two minima at 1.47 (peak-1) and $1.55 \mu \mathrm{m}$ (peak-2) have been fitted with $2^{\text {nd }}$ order polynomials between two extremes $X_{1 i}-X_{1 F}$ and $X_{2 i}-X_{2 F}$, respectively. Bands have been resampled with $10^{3}$ points before polynomial fitting. The area is computed between $X 1-X 2$ and so refers to the area of whole band. C: fitting of the $3-\mu \mathrm{m}$ band. The edges $X_{1}, X_{2}$ for continuum removal have been put at 2.6 and $3.54 \mu \mathrm{m}$, while the $2^{\text {nd }}$ order polynomial has been computed, after a denser resampling, between $X_{2 i} X_{2 F}=3,3.42 \mu \mathrm{m}$. Band edges $X_{1}, X_{2}$ and $X_{2 i} X_{2 F}$ have been chosen appropriately for each analyzed band and each spectrum, and not kept constant for all dataset, in order to take into account variations from one spectrum to another (i.e. variations with temperature and grain size). 


\subsection{Hexahydrite}

\section{1-micron band.}

This band is weak but well defined for each size and temperature (Fig. 1). The absorption's intensity, as well as depth, clearly changes with changing grain size (Figs. 1, 5), whereas for a given grain size there is no trend with temperature (Fig.5b). The position (center) of the absorption (Fig.5a) varies within a narrow range $(0.99$ to $1.01 \mu \mathrm{m})$ and shows a shift towards longer wavelengths with decreasing temperature. The band depth (Fig. $5 \mathrm{~b}$ ) shows a behavior compatible with the absorption area (Fig. $5 \mathrm{c}$ ). The width of the absorption varies within 0.08 and $0.10 \mu \mathrm{m}$ and no trend is observed as a function of size or temperature (Fig. $5 \mathrm{~d}$ ).

\section{2-micron band.}

The second absorption is located inside the shoulder of the strong $1.5 \mathrm{H}_{2} \mathrm{O}$ band. At our spectral resolution this feature is weak, asymmetric, with a less defined minimum for the 20-50 $\mu \mathrm{m}$ size fraction and at the highest temperature for the other sizes (Fig. 1). Moreover at low temperature we have indication of possible absorptions with finer structure, resolvable at higher spectral resolutions. The position of the absorption (Fig. 6a) varies within a narrow range (from 1.20 to $1.22 \mu \mathrm{m}$ ) with decreasing temperature. This shift is almost linear for the 75-100 $\mu \mathrm{m}$ size, whereas the other two sizes show a similar trend but only until $T=173-138 \mathrm{~K}$, while at lower temperatures the position moves back towards $1.21 \mu \mathrm{m}$. This is probably related to the appearance of a new weak minimum within the 1.22-1.23 $\mu \mathrm{m}$ range, not well resolvable at the considered spectral resolution. The absorption depth slightly increases with the size and inversely with temperature (Fig. 6b). The band area also increases directly with the size, and inversely with temperature (Fig. $6 \mathrm{c})$. The width (FWHM) is $0.10 \mu \mathrm{m}$ and no trend is observed as a function of size or temperature (Fig. 6d).

\section{5-micron band.}

The $\mathrm{OH}$ absorption band at $\sim 1.5 \mu \mathrm{m}$ is actually due to a combination of three weaker features centered at $1.47,1.55$, and $1.61 \mu \mathrm{m}$, respectively. This band appears as a triplet only at cryogenic temperatures, while it is a doublet at ambient temperature. Concerning the $1.47 \mu \mathrm{m}$ feature, all four parameters have been computed for the three grain sizes; the trends are shown in Fig. 7. The band position (fig.7a) slightly shifts towards longer wavelengths as the temperature decreases. The depth increases substantially as the temperature decreases (fig.7b). The band area (fig.7c) tends to greater values towards lower temperatures. The band gets narrower (fig.7d). 
Regarding the $1.55 \mu \mathrm{m}$ band, all parameters were computed: position, depth, area and width (Fig. 8). The position of this feature (Fig. 8a) was computed for temperatures below $223 \mathrm{~K}$, and no significant trend is evident. The depth shows a strong dependence with temperature: again the depth increases with decreasing temperature (Fig. 8b). Both area (Fig.8c) and width (Fig. 8d) show an overall dependence with temperature, with a general increase towards lower $T$ values, although these two parameters are quite constant in the range $T=113 \div 173 \mathrm{~K}$. Band centers at 1.47 and $1.55 \mu \mathrm{m}$ seem to be correlated. The $1.61-\mu \mathrm{m}$ feature is very weak and only shows up at very low temperatures, i.e. below $173 \mathrm{~K}$. At higher temperatures, this feature and the central feature at $1.55 \mu \mathrm{m}$ merge together. As temperature raises up to room values, the $1.55-\mu \mathrm{m}$ band becomes hardly recognizable and only the feature at $1.47 \mu \mathrm{m}$ remains detectable (see Discussion in Section 4). Band parameters for the 1.61- $\mu \mathrm{m}$ feature have not been computed in this analysis.

\section{9-micron band.}

The band parameters computed for the water band at $1.9 \mu \mathrm{m}$ are shown in Fig. 9. The band center (fig.9a) shifts towards longer wavelengths from about $1.95 \mu \mathrm{m}$ to $1.97 \mu \mathrm{m}$ when cooling from room temperature down to 93K. Both the band depth (Fig. 9b) and band area (Fig. 9c) show an increase towards lower temperatures. No significant temperature dependence has been retrieved for the band width (Fig. 9d).

\section{2-micron band.}

The trends are shown in Fig. 10. While the band center (Fig. 10a) does not show any particular trend, band depth and band area display a correlation with changing temperature. Both depth (Fig. 10b) and area (Fig. 10c) become greater as the temperature decreases. This weak band becomes even more evident and recognizable at very low temperatures. Band width (fig.10d) gets greater at low $T$ at least for the grain sizes 20-50 and 75-100 $\mu \mathrm{m}$.

\section{3-micron band.}

This band is related to a combination of transitions in $\mathrm{OH}^{-}$and $\mathrm{H}_{2} \mathrm{O}$ (Cloutis et al., 2006). Position, depth and area show neat correlation with the temperature variation (Fig. 11): as the temperature decreases, the band position (Fig. 11a) shifts towards shorter wavelengths in the range 3.0-3.1 $\mu \mathrm{m}$, for the grain sizes 20-50 and 75-100 $\mu \mathrm{m}$. Conversely, the band position of coarser grain size (125-150 $\mu \mathrm{m})$ does not show any obvious correlation with temperature. Its depth increases with decreasing temperature (Fig. 11b); moreover the fine powder shows the largest values of band depth, while the coarse powder shows the smallest values of depth; the medium powder showing intermediate values. The water band area (Fig. 11c) tends to decrease as the temperature drops 

decreases.
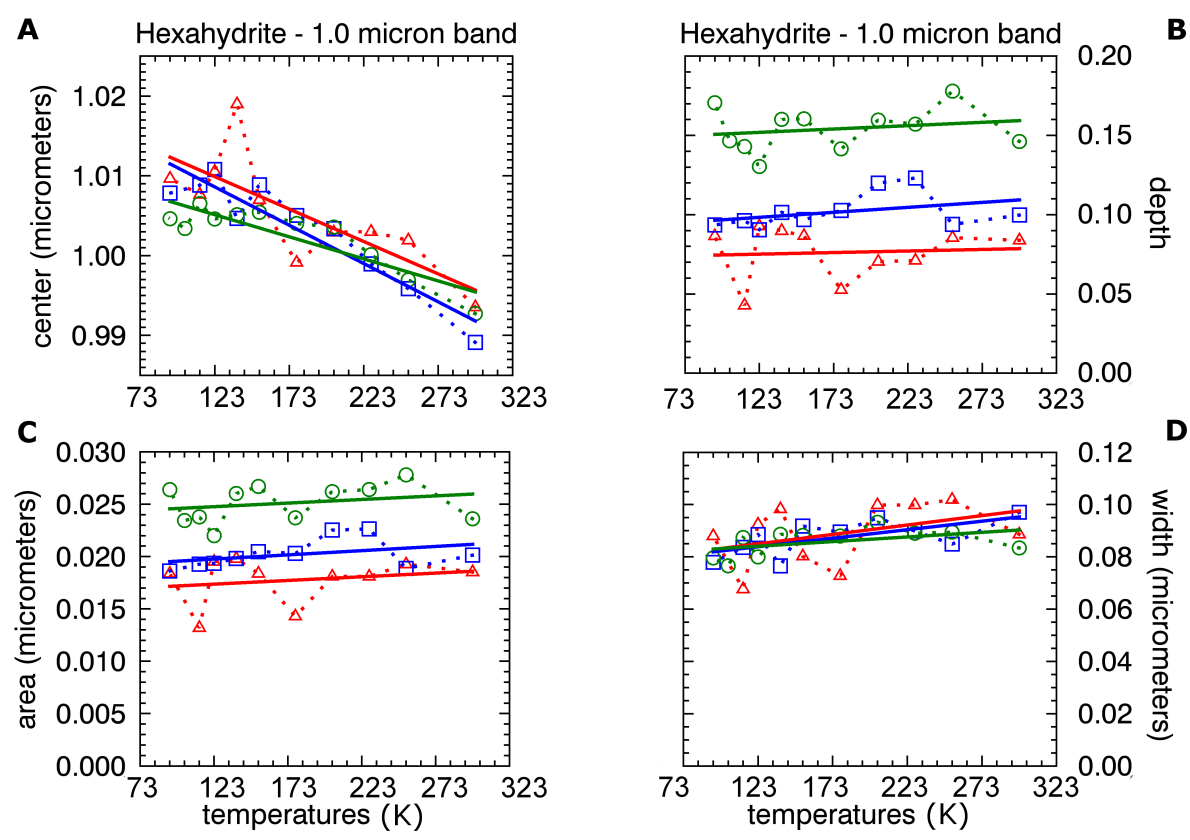

Fig.5. Band parameters determined for the band at $1.0 \mu \mathrm{m}$, hexahydrite. Red triangles: grain size 20-50 $\mu \mathrm{m}$. Blue squares: 75-100 $\mu \mathrm{m}$. Green circles: 125-150 $\mu \mathrm{m}$.
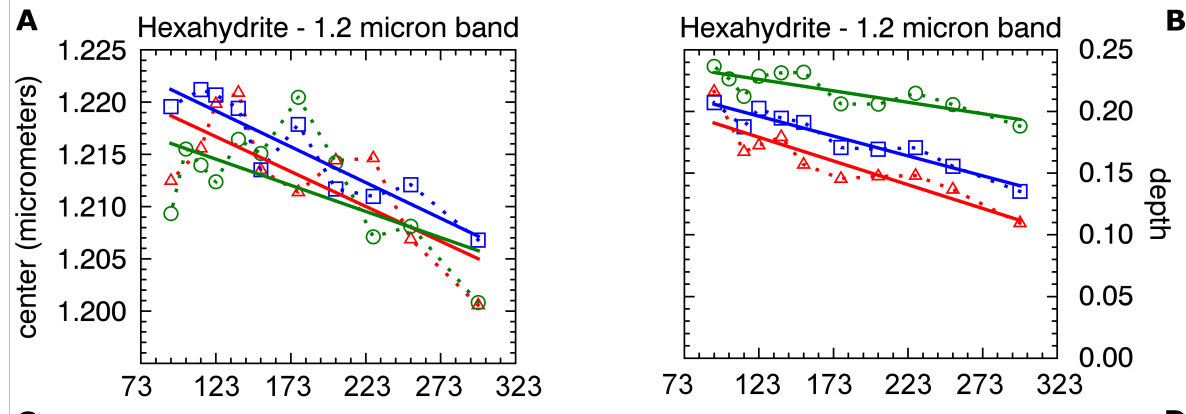

\section{C}

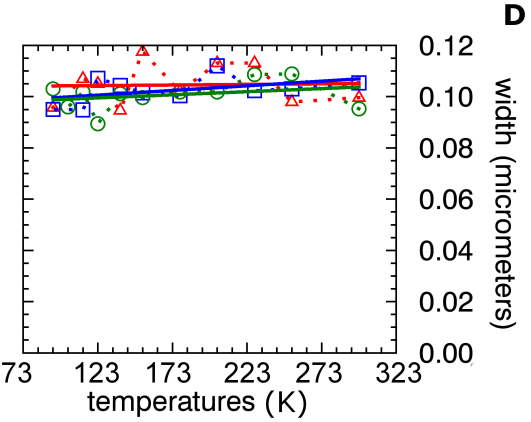

Fig.6. Band parameters determined for the band at $1.2 \mu \mathrm{m}$, hexahydrite. Red triangles: grain size 20-50 $\mu \mathrm{m}$. 

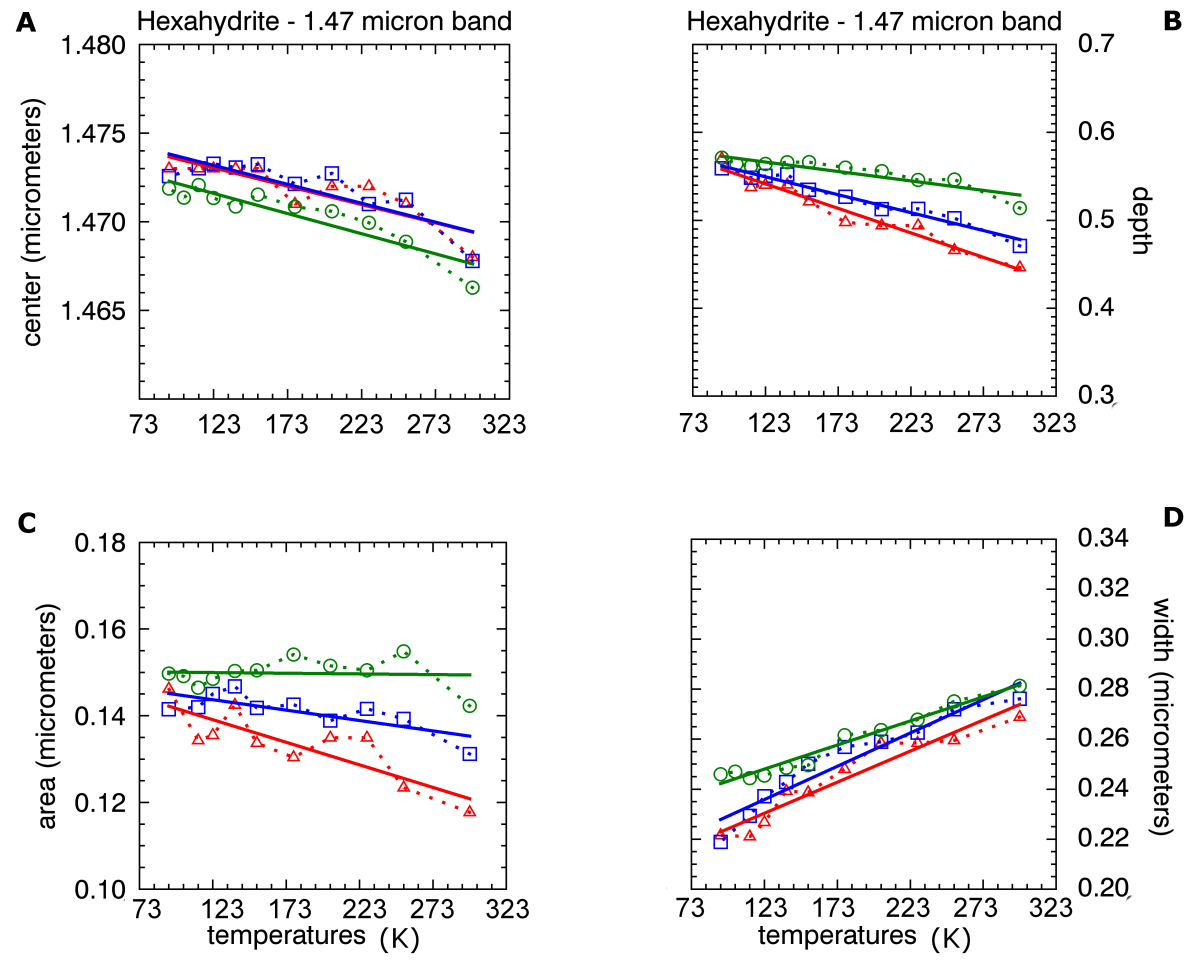

Fig.7. Band parameters determined for the band at $1.47 \mu \mathrm{m}$, hexahydrite. Red triangles: grain size 20-50
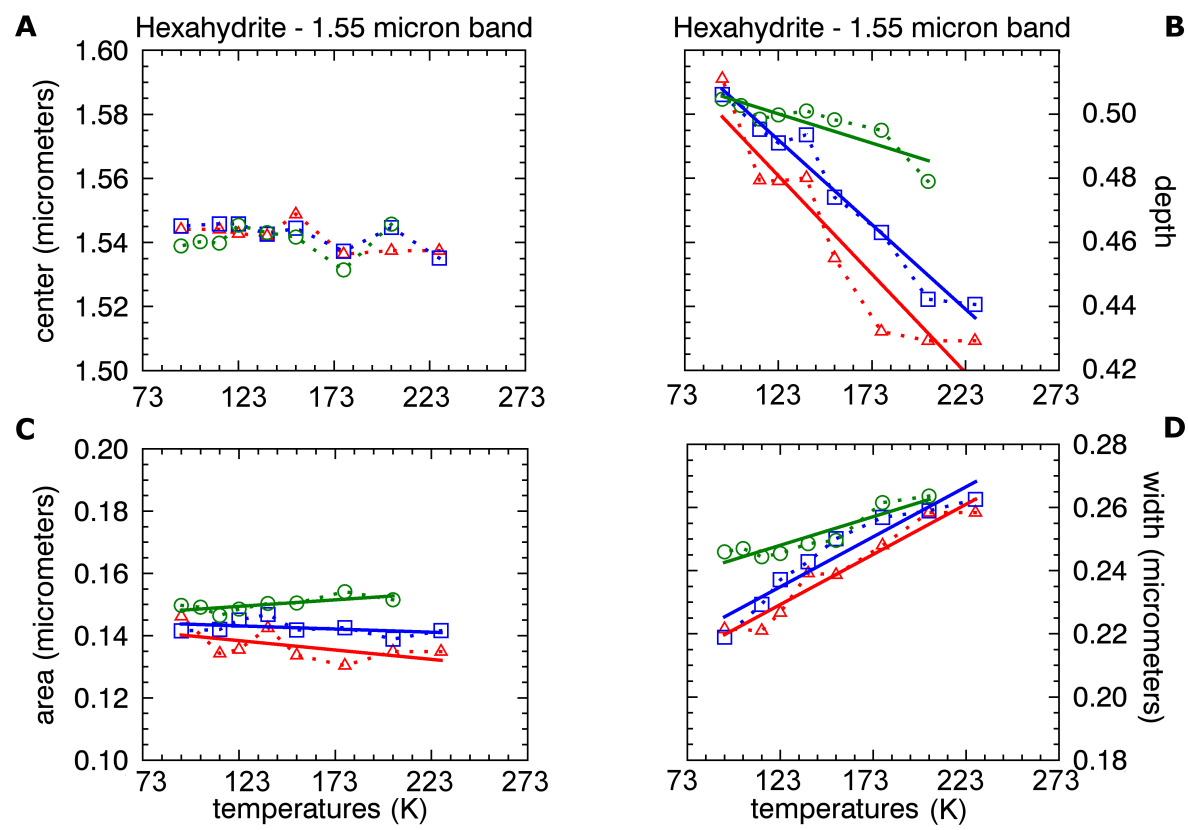

Fig.8. Band parameters determined for the band at $1.55 \mu \mathrm{m}$, hexahydrite. Red triangles: grain size 20-50 um. Blue squares: 75-100 um. Green circles: 125-150 $\mu \mathrm{m}$. 

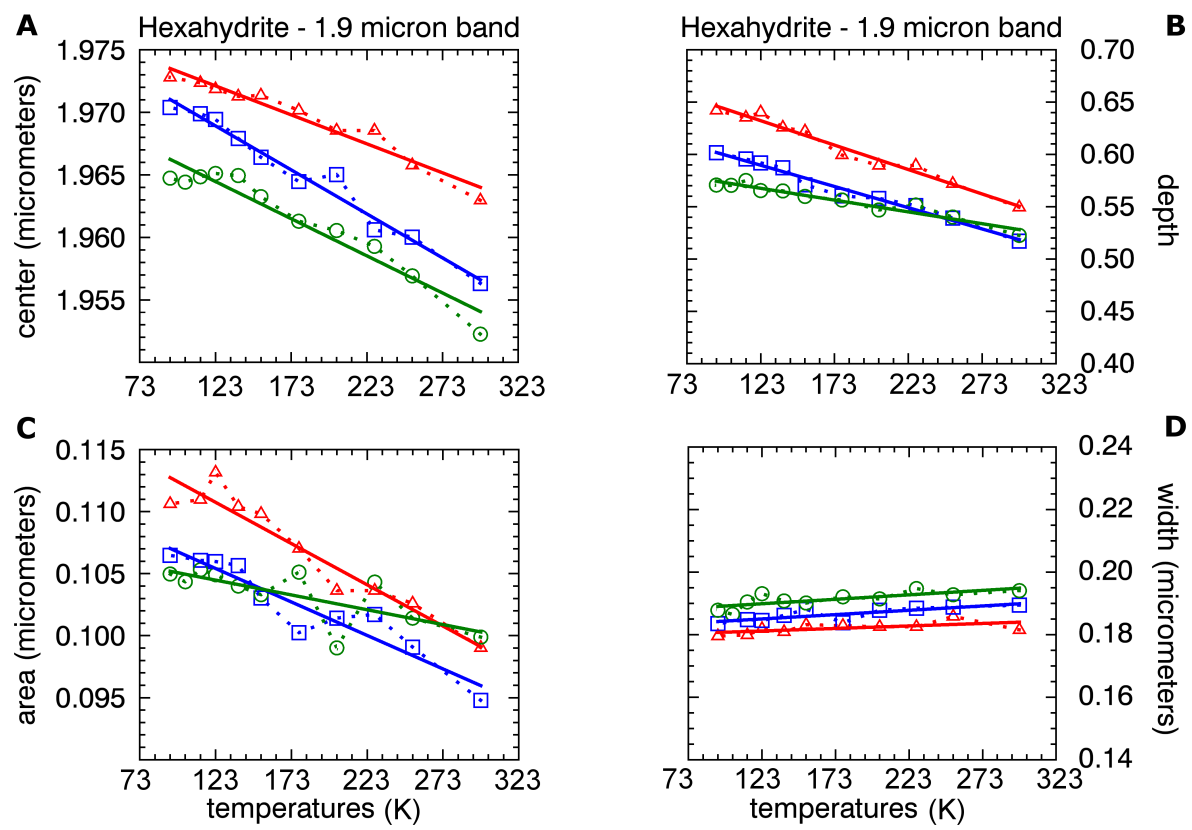

Fig.9. Band parameters determined for the band at $1.9 \mu \mathrm{m}$, hexahydrite. Red triangles: grain size 20-50 $\mu \mathrm{m}$. Blue squares: 75-100 $\mu \mathrm{m}$. Green circles: 125-150 $\mu \mathrm{m}$.
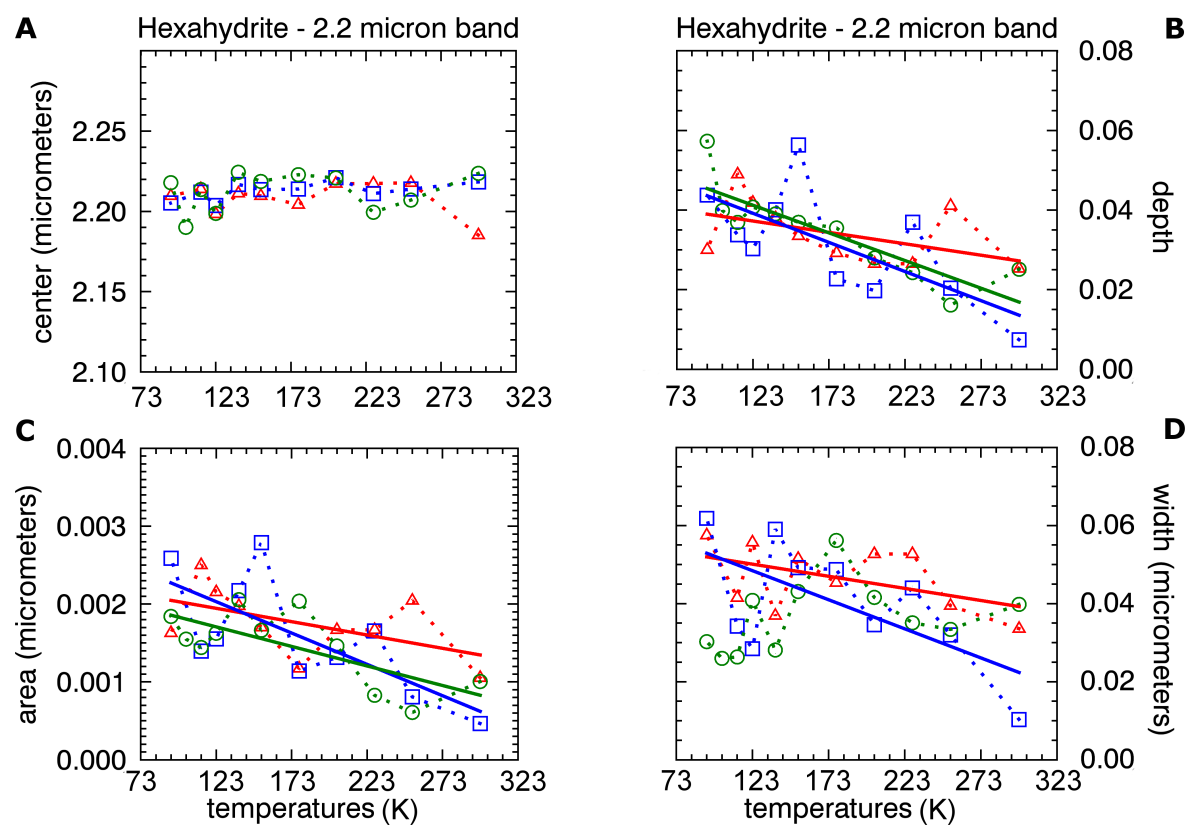

Fig.10. Band parameters determined for the band at $2.2 \mu \mathrm{m}$, hexahydrite. Red triangles: grain size 20-50 um. Blue squares: 75-100 $\mu \mathrm{m}$. Green circles: 125-150 $\mu \mathrm{m}$. 

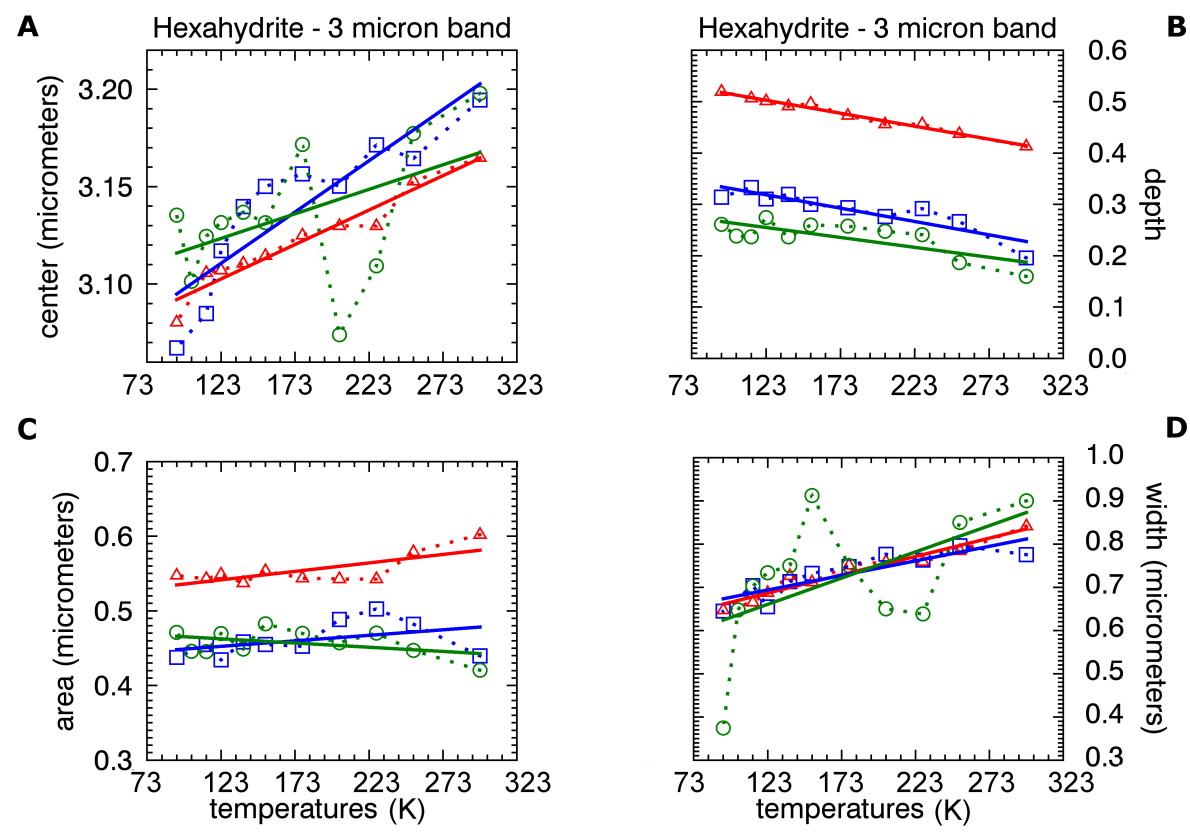

Fig.11. Band parameters determined for the band at $3 \mu \mathrm{m}$, hexahydrite. Red triangles: grain size 20-50 $\mu \mathrm{m}$. Blue squares: 75-100 $\mu \mathrm{m}$. Green circles: 125-150 $\mu \mathrm{m}$.

\subsection{Epsomite}

1-micron band.

Also for epsomite this band is weak, but well defined for each grain size and temperature (Fig. 2). The absorption's center (Fig.12a) varies within 1.00 and $1.03 \mu \mathrm{m}$, showing a shift with temperature. As well as for hexahydrite, the position moves to longer wavelengths with decreasing temperature. This trend is almost linear for 75-100 and 125-150 $\mu \mathrm{m}$, whereas for the smallest size it shows a steep variation between 223 and 173K. The strong asymmetry seen for lower temperatures could suggest a possible shift towards longer wavelengths, if the absorption could be sampled at higher spectral resolution. The absorption intensity, as both depth and area, slightly varies within narrow ranges without defined trends with size and temperature (Fig.12b,c). The width (FWHM) of absorption is around $0.9 \mu \mathrm{m}$ (Fig.12d).

\section{2-micron band.}

This absorption takes place inside the strong 1.5- $\mu \mathrm{m}_{2} \mathrm{O}$ absorption, and a defined band is actually observed only for the 120-150 $\mu \mathrm{m}$ size. Lower sizes show a bent, with the possible presence of relative minima, not resolved with our setup. For the 120-150 $\mu \mathrm{m}$ size the absorption is weak and asymmetric (Fig. 2). The position of the absorption (Fig. 13a) slightly varies from 1.21 to $1.22 \mu \mathrm{m}$ with decreasing temperature. A finer structure across the band minimum is outlined but not well resolvable. The absorption depth slightly increases with grain size and inversely with 
temperature (Fig.13b), whereas the band area shifts around 0.02 (Fig. 13c). The band width is 0.10 $\mu \mathrm{m}$ (Fig.13d).

\section{5-micron band.}

Like hexahydrite, epsomite shows a prominent $\mathrm{OH}^{-}$band centered near $1.5 \mu \mathrm{m}$, which in this case is the combination of a doublet of absorptions, centered at about 1.5 and $1.62 \mu \mathrm{m}$. These two signatures become more distinctly resolvable as the temperature decreases. The parameters computed for the 1.5- $\mu \mathrm{m}$ feature are shown in Fig. 14. This band center (Fig. 14a) shifts towards longer wavelengths in the range 1.48-1.50 $\mu \mathrm{m}$ as the temperature decreases. Band depth (Fig. 14b) and band area (Fig. 14c) show similar trends: both become larger as the temperature decreases. The width becomes narrower towards lower values of temperature (Fig. 14d).

The parameters of the secondary feature at $1.62 \mu \mathrm{m}$ are shown in Fig. 15. All the parameters are characterized by monotonous trends, similar to those related to the $1.5-\mu \mathrm{m}$ signature. The band center (Fig. 15a) shifts towards longer wavelengths in the range 1.59-1.63 $\mu \mathrm{m}$ as the temperature decreases down to $93 \mathrm{~K}$. Again, band depth and band area (Fig. 15b,c) show an increase as the temperature decreases. Similar to the $1.5-\mu \mathrm{m}$ feature, the $1.62-\mu \mathrm{m}$ feature is characterized by a width that becomes narrower as the temperature decreases (Fig. 15d).

\section{9-micron band.}

The parameters relative to the $\mathrm{H}_{2} \mathrm{O}$ absorption band are displayed in Fig. 16. They show an evident correlation with temperature, except for the width. The band center (Fig. 16a) shifts towards longer wavelengths in the range 1.96-1.98 $\mu \mathrm{m}$ as the temperature decreases. Band depth and area (Fig. 16b,c) are both characterized by an increase towards lower values of temperature. The width shows no trend (fig.16d).

\section{3-micron band.}

The prominent water absorption feature centered at approximately $3 \mu \mathrm{m}$ is difficult to analyze for grain sizes $75-100 \mu \mathrm{m}$ and $125-150 \mu \mathrm{m}$, because saturation affects the spectra above $2.3 \mu \mathrm{m}$. Thus the 3- $\mu \mathrm{m}$ feature has been only analyzed for the grain size 20-50 $\mu \mathrm{m}$ (Fig. 17). The left and right shoulders of the band have been chosen near 2.6 and $3.7 \mu \mathrm{m}$, respectively. With a shoulder taken at $2.6 \mu \mathrm{m}$, a band centered near $2.5 \mu \mathrm{m}$ shows up. But this is only evident for 20-50 $\mu \mathrm{m}$ grain size, and it has not been considered here. As for the hexahydrite, the band position (Fig. 17a) shifts towards shorter wavelengths as the temperature decreases, in the range 3.04-3.12 $\mu \mathrm{m}$. The band depth (Fig. 17b) is characterized by a strong increasing trend while the temperature drops down. 
408
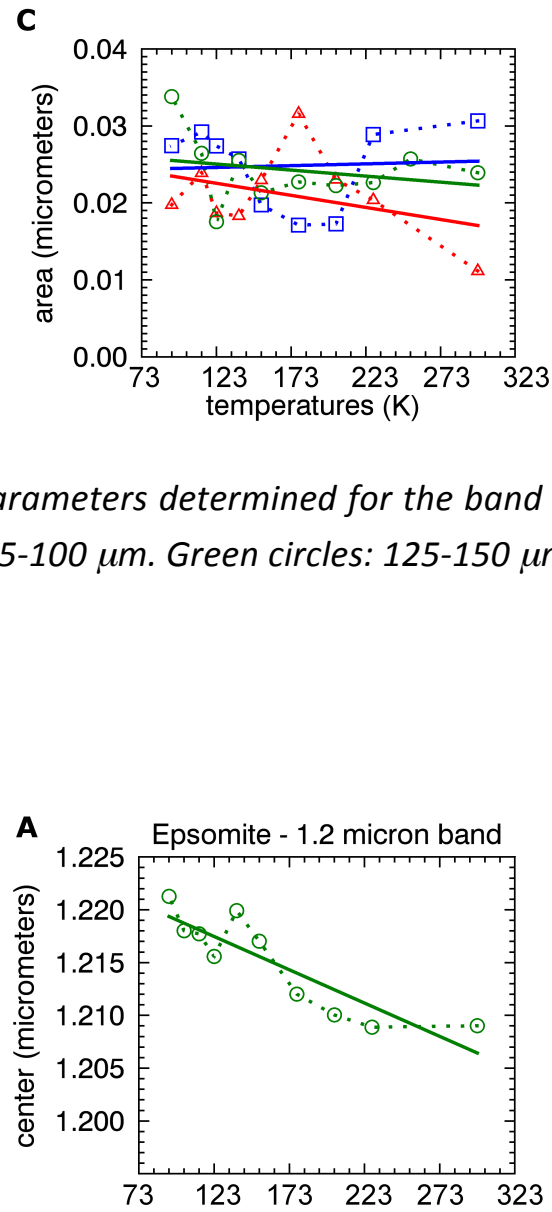
Blue squares: 75-100 $\mu \mathrm{m}$. Green circles: 125-150 $\mu \mathrm{m}$.

\section{C}

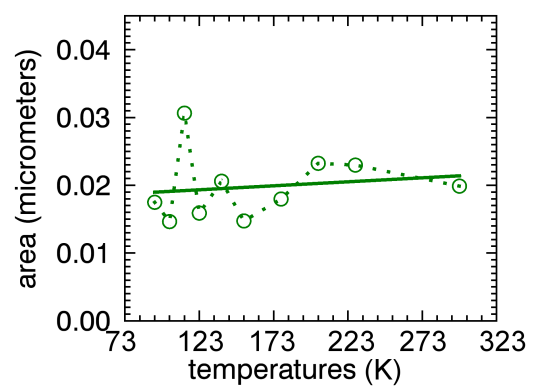

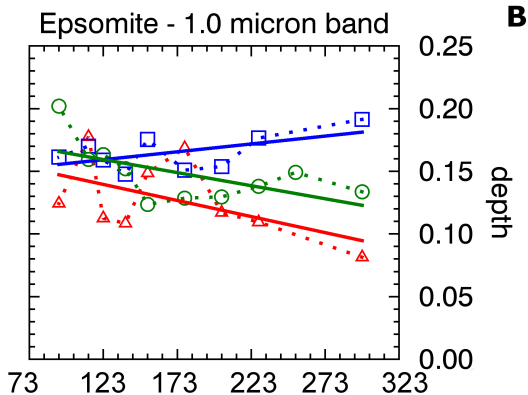

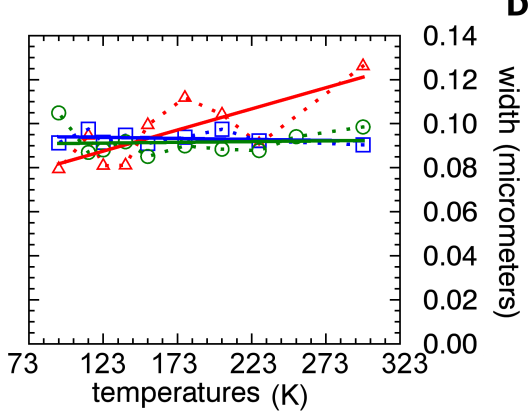

Fig.12. Band parameters determined for the band at $1.0 \mu \mathrm{m}$, epsomite. Red triangles: grain size 20-50 $\mu \mathrm{m}$.
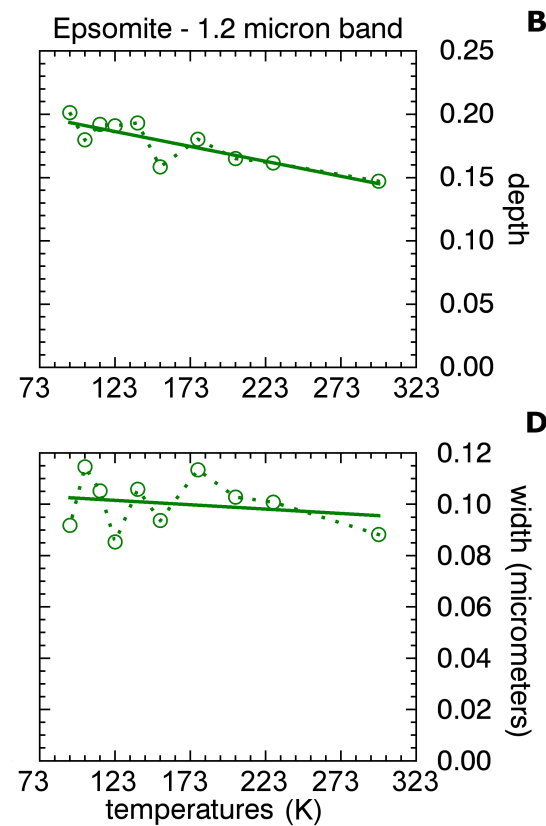

Fig.13. Band parameters determined for the band at $1.2 \mu \mathrm{m}$, epsomite. Green circles: 125-150 $\mu \mathrm{m}$. 

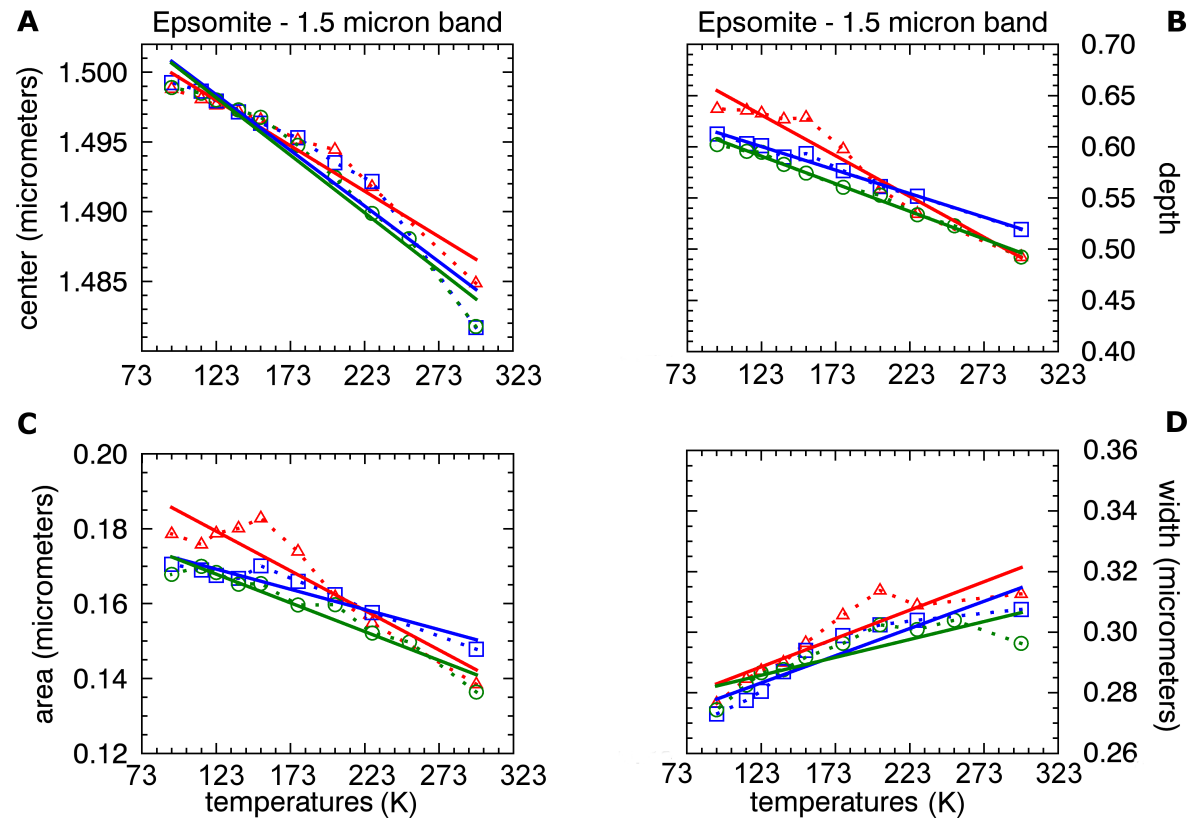

Fig.14. Band parameters determined for the band at $1.5 \mu \mathrm{m}$, epsomite. Red triangles: grain size 20-50 $\mu \mathrm{m}$.
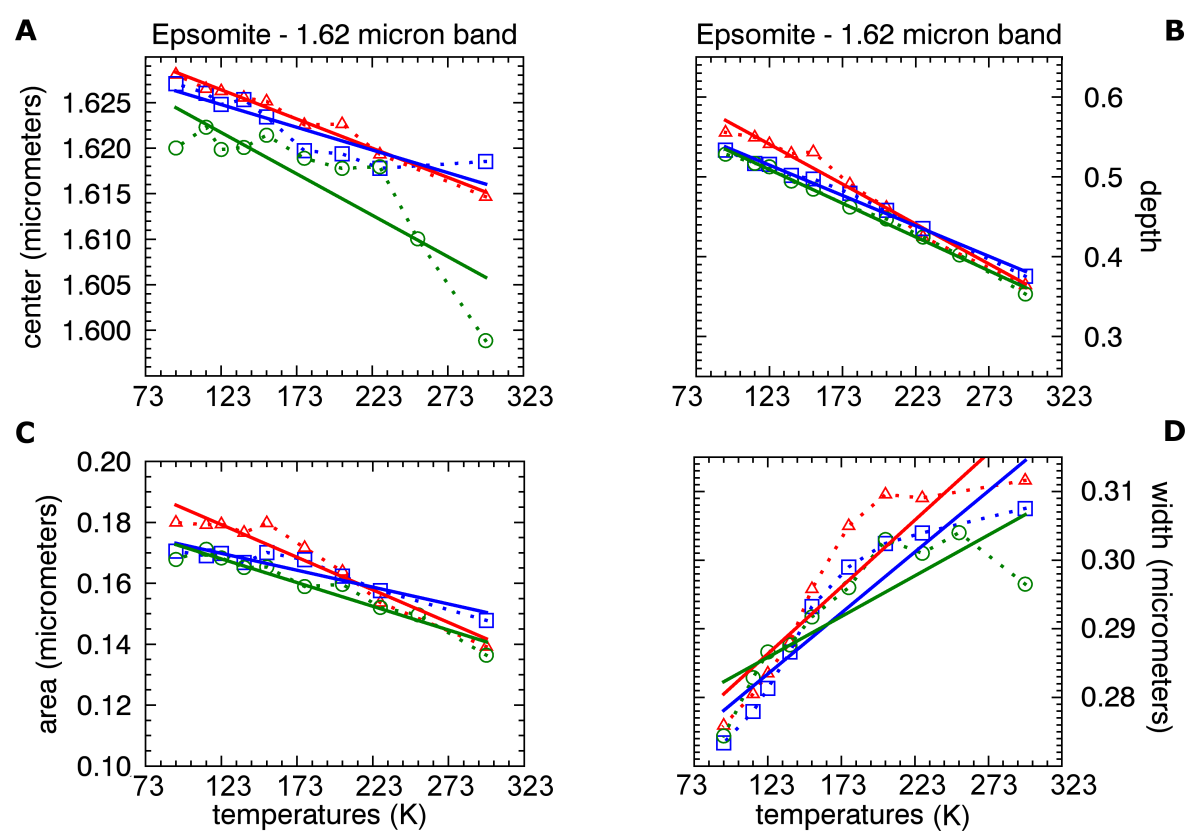

Fig.15. Band parameters determined for the band at $1.62 \mu \mathrm{m}$, epsomite. Red triangles: grain size 20-50 $\mu \mathrm{m}$. 

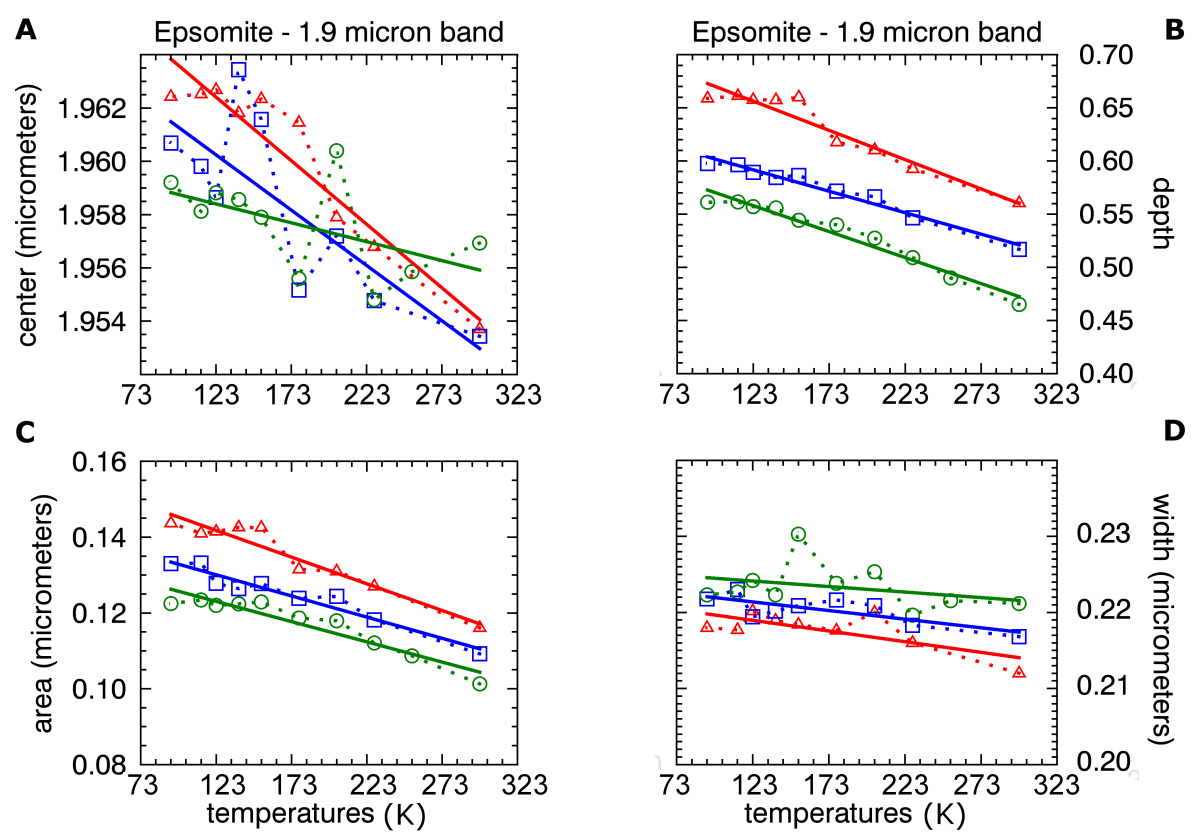

430 Fig.16. Band parameters determined for the band at $1.9 \mu \mathrm{m}$, epsomite. Red triangles: grain size 20-50 $\mu \mathrm{m}$. 431 Blue squares: 75-100 $\mu \mathrm{m}$. Green circles: 125-150 $\mu \mathrm{m}$.
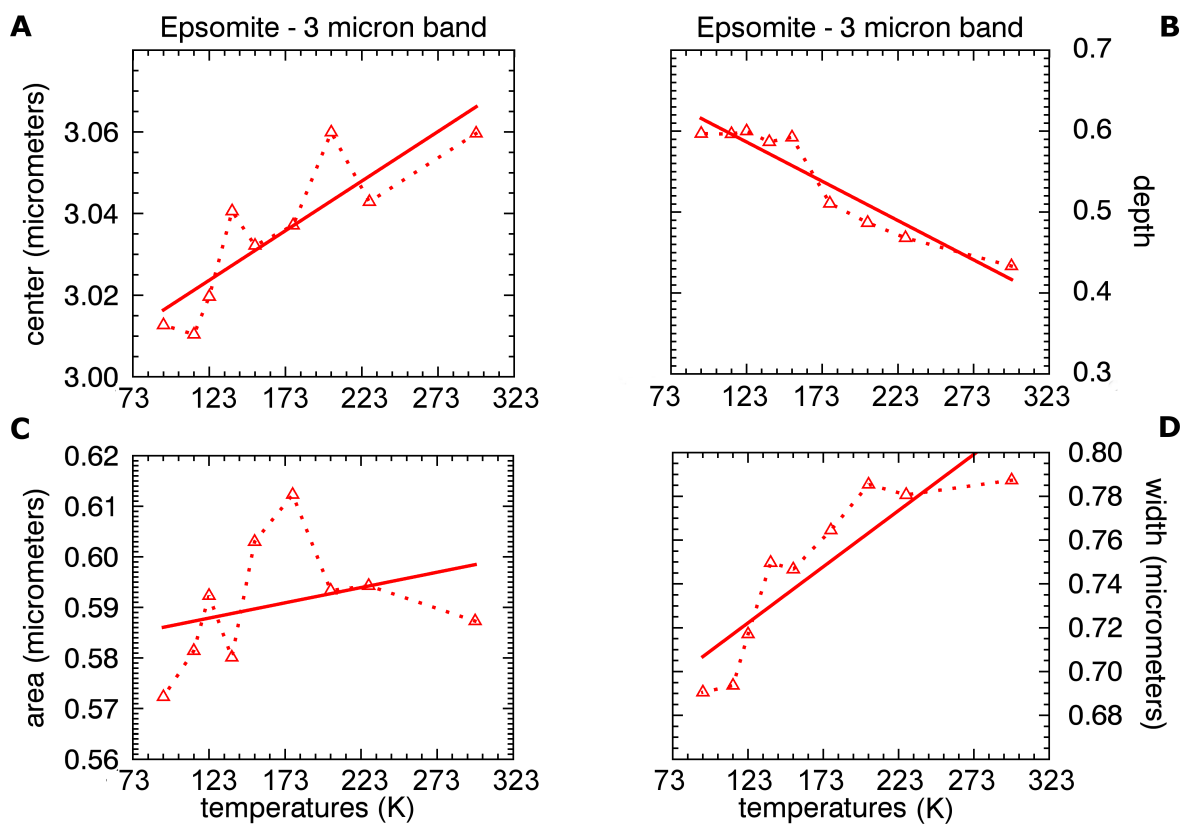

Fig.17. Band parameters determined for the band at $3 \mu \mathrm{m}$, epsomite. Red triangles: grain size 20-50 $\mu \mathrm{m}$. 
Hexahydrite and epsomite spectra show overtone absorptions in similar spectral ranges but some differences are visible. The most evident variation is in the $\mathrm{H}-\mathrm{O}-\mathrm{H} / \mathrm{O}-\mathrm{H}$ bands near $1.5 \mu \mathrm{m}$ (Figs. 1,2 and Fig.18a), and the other two most different absorptions are those related to $\mathrm{H}_{2} \mathrm{O}$, in particular the 1.9/2 $\mu \mathrm{m}$ feature (Fig. 19).

\section{Hexahydrite vs Epsomite at $1.5 \mu \mathrm{m}$}

Hexahydrite's $1.5-\mu \mathrm{m}$ absorption shows a triplet/three minima profile, which becomes more and more evident as the sample is cooled down to $93 \mathrm{~K}$ (Fig.18a), whereas epsomite's 1.5- $\mu \mathrm{m}$ signature has a doublet/two minima shape (Fig. 18b) at all temperatures. At room temperature, hexahydrite feature becomes a broad band with a single minimum centered at about $1.47 \mu \mathrm{m}$.

In the fine structure of the whole absorption band (between 1.32 and $1.83 \mu \mathrm{m}$ ) for spectra acquired at low temperature for both samples, we can discern three additional weak features. These can be recognized at the spectral resolution of about $24 \mathrm{~nm}$ in this range (see section 2.1).

McCord et al. (1999) pointed out that the fine structure of hexahydrite spectrum at $77 \mathrm{~K}$ consists of six absorption features, as measured in laboratory at a spectral resolution of $10 \mathrm{~nm}$. In their study, McCord et al. (1999) suggested that the number of absorption transitions, in the $\mathrm{H}-\mathrm{O}-\mathrm{H} / \mathrm{O}-\mathrm{H}$ feature fine structure at $1.5 \mu \mathrm{m}$, could be proportional to each site in the mineral crystal structure occupied by a water molecule. However, Cloutis et al. (2006) reported the existence of two minima centered at 1.44 and $1.46 \mu \mathrm{m}$ within the fine structure of hexahydrite's $1.5-\mu \mathrm{m}$ band as measured at room temperature, stating that all these signatures are $\mathrm{H}_{2} \mathrm{O}$ overtones/combinations. They also interpret small minima in the fine structure of bands occurring in the 1.4-1.5- $\mu \mathrm{m}$ region in other sulfates as related to $\mathrm{OH}^{-}$or $\mathrm{H}_{2} \mathrm{O}$ overtones and combinations (Cloutis et al., 2006). Dalton et al. (2005) and Dalton and Pitman (2012) refer to the band in the 1.4-1.6- $\mu \mathrm{m}$ region of hexahydrite/epsomite as related to $\mathrm{O}-\mathrm{H}$ stretching overtones. The fine structure of these features, as observed at cryogenic temperatures, could be related to $\mathrm{OH}^{-}$groups occupying different locations in the crystal lattice (Dalton et al., 2005, and references therein). 


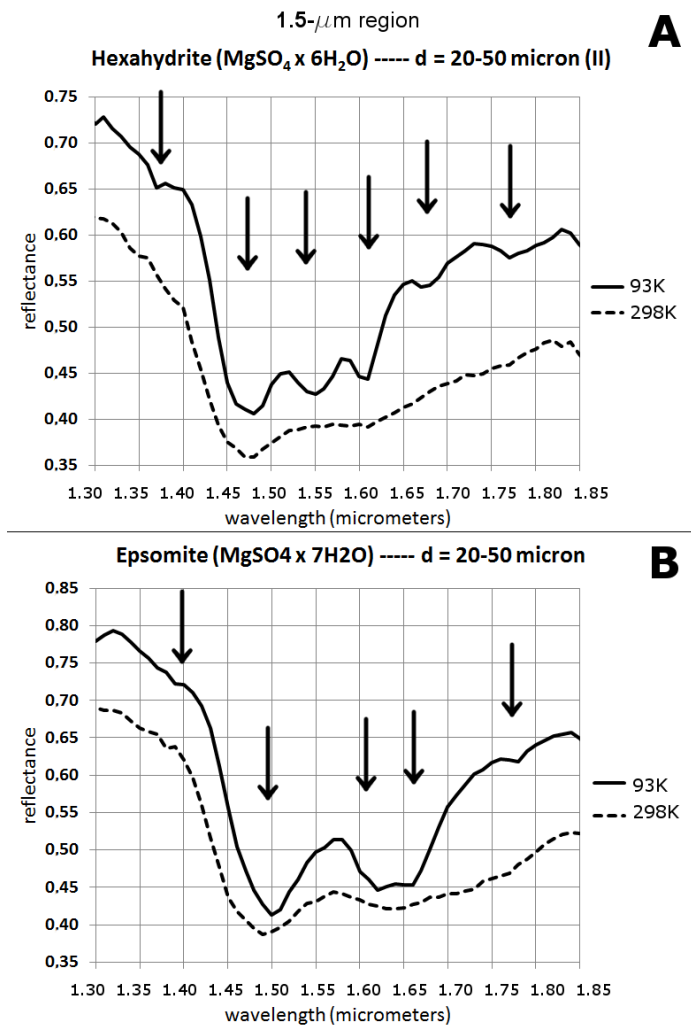

Fig.18. $\mathrm{OH}$ absorption band at $1.5 \mu \mathrm{m}$. A: hexahydrite. B: epsomite. For each sample, the line-curve is at $93 \mathrm{~K}$, while the dashed curve is at room temperature (shifted for clarity).

469 Prominent differences between hexahydrite and eposmite are those related to $\mathrm{H}_{2} \mathrm{O}$, in particular the 1.9/2 um feature (Fig. 19). This absorption shows a better defined V-shape with a clear 471 minimum for all temperatures and all sizes in hexahydrite (Fig. 19a), whereas epsomite shows a 472 less defined minimum (Fig. 19b). This absorption is probably characterized by several minima at 473 low temperature, even though our spectral resolution did not allow us to unambiguously resolve 474 them. The 3- $\mu \mathrm{m}$ band is well defined for smaller sizes and lower temperatures, but it is still 475 detectable also for the other sizes (75-100 $\mu \mathrm{m}$ and 125-150 $\mu \mathrm{m}$ ) in hexahydrite spectra. 476 Conversely, epsomite shows a saturated plateau at wavelength $>2.3 \mu \mathrm{m}$ for coarser grain sizes, 477 because it contains more water (Figs. 1,2). 

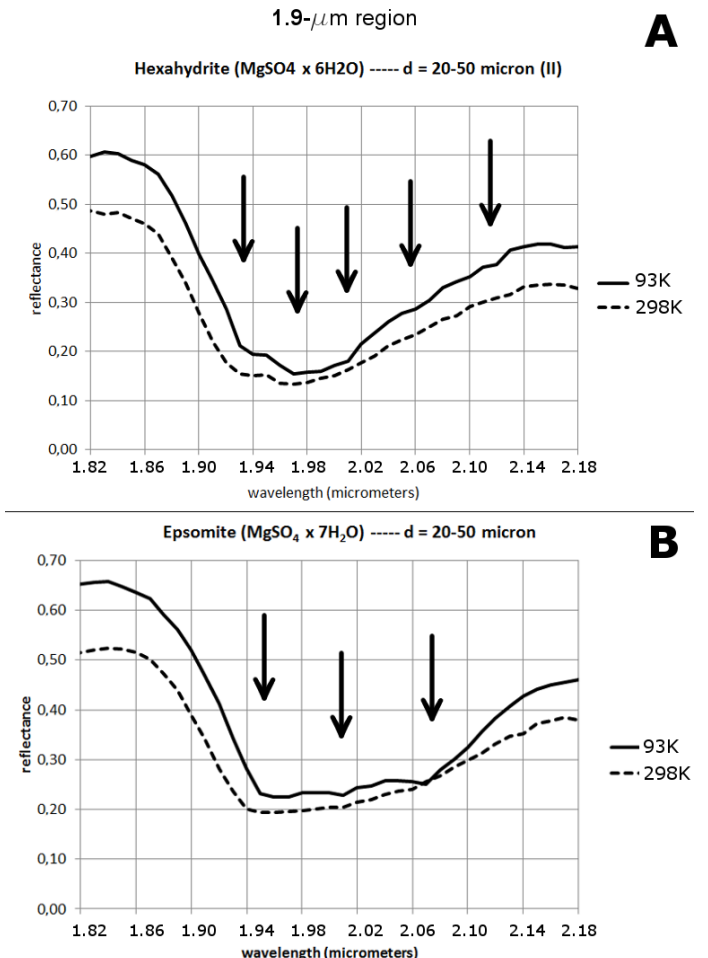

Fig.19. $\mathrm{H}_{2} \mathrm{O}$ absorption band at $1.9 \mu \mathrm{m}$. A: hexahydrite. B: epsomite. For each sample, the line-curve is at $93 \mathrm{~K}$, while the dashed curve is at room temperature (shifted for clarity).

\section{Band ratio at $1.5 \mu \mathrm{m}$}

We have investigated the relative strengths of individual minima constituting the hexahydrite triplet and the epsomite doublet. The ratio of 1.47 to $1.55 \mu \mathrm{m}$ band depths in hexahydrite has an evident increasing profile with increasing temperature (Fig. 20a): at cryogenic temperatures, the $1.55 \mu \mathrm{m}$ band becomes clearer and more prominent, while at room temperature the $1.47 \mu \mathrm{m}$ band is dominant. Similarly, in Fig. 20b the depth ratio $1.50-\mu \mathrm{m} / 1.62-\mu \mathrm{m}$ is shown. A similar trend shows up for all of the three grain sizes, as already mentioned for the analogous band of hexahydrite. The depth ratio decreases in a monotonous manner as the temperature decreases: at high temperatures the $1.5-\mu \mathrm{m}$ feature is predominant, while at low temperatures the 1.62- $\mu \mathrm{m}$ minimum becomes important and comparable with the former one. The increasing separation, narrowing and definition of these bands occurring towards cryogenic temperatures is attributed to a decreasing thermal agitation of the molecular species in the mineral structure; the distribution of intermolecular couplings narrows and discrete absorption bands arise from both decreasing width and increasing peak intensity of closely spaced bands (Dalton et al., 2005). At the same time as the number of water molecules in the structure increases, the absorption bands tend to be larger and broader, due to the increased range of transition energies and probabilities with enhanced number of molecular vibrations combinations (McCord et al., 1999; Dalton et al., 2005). 

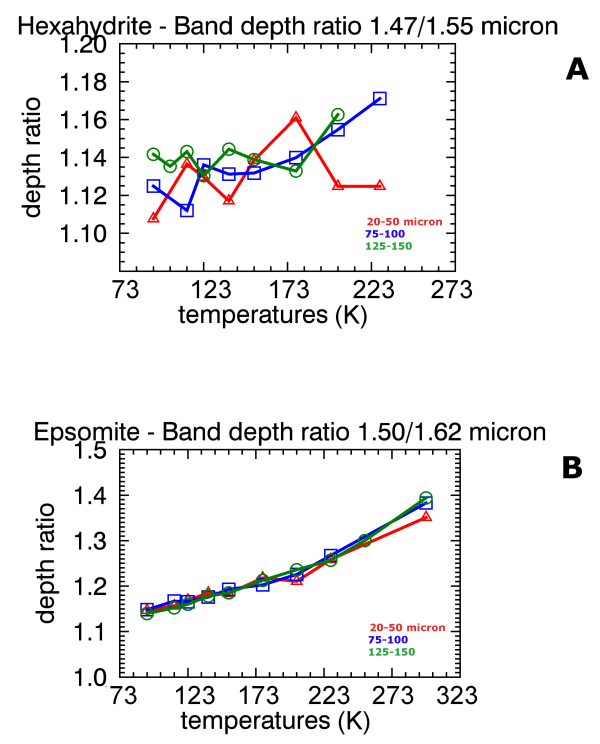

Fig.20. A: depth ratio for the bands at 1.47 and $1.55 \mu \mathrm{m}$ (hexahydrite). B: depth ratio for the bands at 1.50 and 1.62 um (epsomite).

\section{Band position of water 3- $\mu$ m band vs other features}

Concerning band positions, different behaviors are observed if we consider the water band at 3 $\mu \mathrm{m}$ or the other features. Indeed, in both hexahydrite and epsomite, the 3- $\mu \mathrm{m}$ band position shifts towards shorter wavelengths as the temperature decreases to cryogenic values (Fig. 11 and 17). This is particularly observed for the grain sizes 20-50 $\mu \mathrm{m}$ (both samples) and 75-100 $\mu \mathrm{m}$ (hexahydrite). The band position for the $3-\mu \mathrm{m}$ band was difficult to compute for the larger grain sizes because of the saturation of the band. In the case of epsomite, the higher number of water molecules causes the band saturation to occur also at intermediate grain size (75-100 $\mu \mathrm{m})$. Although some authors report that the water band at $3 \mu \mathrm{m}$ is insensitive to temperature variations (Jamieson et al., 2012), here we observe some correlation as mentioned above. On the other hand, when we look at all the other absorption features, we can see that band positions shift towards longer wavelengths. For hexahydrite, the 1.9- $\mu \mathrm{m}$ band position shows a systematic correlation with temperature, with the band center shifting towards longer wavelengths at cryogenic temperatures (hexahydrite, Fig. 9). For epsomite, the features at 1.5, 1.62 and $1.9 \mu \mathrm{m}$ all show a correlation with $\mathrm{T}$, again shifting towards longer wavelengths at cryogenic temperatures. We note that in water ice the corresponding absorption bands at $1.5,1.65$, and $1.99 \mu \mathrm{m}$ also display strong spectral shifts in the same direction (Grundy and Schmitt 1998). The band area also shows different trends with decreasing temperature: it becomes larger for all absorption features in both materials, except the $3-\mu \mathrm{m}$ band, for which a decrease at cryogenic temperatures is observed. The different behavior of the 3- $\mu \mathrm{m}$ band with respect to the other features described previously could be attributed to the fact that the $\mathrm{H}_{2} \mathrm{O}$-band tends to become deeper and narrower at low temperatures: the high wavelength edge shifts towards shorter wavelengths (Fig. 1 and 2). 
528 In order to interpret remote-sensed data and to discriminate among different types of hydrated 529 sulfates, however, the 3- $\mu \mathrm{m}$ feature seems to be in any case poorly diagnostic, in particular due to its high degree of saturation linked to the high water content of these minerals. It is discernible in hexahydrite for the grain sizes 20-50 and 75-100 $\mu \mathrm{m}$, while in epsomite it is only recognizable for the smallest grain size. Moreover, it is hard to retrieve a precise band center, due to band broadness or because it saturates and loses individuality. On the contrary, the features at 1.5 and $1.9 \mu \mathrm{m}$ prove to be more diagnostic for mineral discrimination. At cryogenic temperatures, hexahydrite and epsomite can be fundamentally discriminated by looking at: (i) the fine structure of the $1.5-\mu \mathrm{m}$ band, which is resolved into a triplet (hexahydrite) or into a doublet (epsomite) at spectral resolution of about $20 \mathrm{~nm}$, and (ii) the 1.9- $\mu \mathrm{m}$ band, which has a defined V-shape at low temperatures (hexahydrite) or appears more flattened and composed by different minima (epsomite). The JUICE/MAJIS spectrometer (Piccioni et al., 2014; Langevin et al., 2014) with its high spectral sampling (3-7 $\mathrm{nm}$ in the 0.4-5.7- $\mathrm{mm}$ spectral range) will have great possibilities to discriminate among the different mineralogical phases on the surface of the icy Galilean satellites.

\section{Conclusions}

We have performed spectroscopic analyses on two poly-hydrated magnesium sulfates, hexahydrite and epsomite, in the visible and infrared range 0.5-4.0 $\mu \mathrm{m}$; our measurements have been carried out at different temperatures, from room temperature ( $298 \mathrm{~K}$ ) down to cryogenic values (minimum value being $\sim 93 \mathrm{~K}$ ). The obtained spectra of these samples and the subsequent derivation of band parameters has allowed us to investigate the fine structure of several absorption features arising at cryogenic temperatures. The spectra of hydrated sulfates are dominated by absorptions due to $\mathrm{OH}$ ions and $\mathrm{H}_{2} \mathrm{O}$ molecules present in the mineral structure; trends of band parameters vs. temperature have been derived, showing a general narrowing and refining of bands, together with slight shifts of their positions.

Laboratory investigations of hydrated minerals, by means of visible and infrared spectroscopy, are key to support the interpretation of remote sensing data returned by ongoing interplanetary missions (e.g., NASA/Dawn) and future missions currently under implementation (e.g., ESA/ExoMars 2020, NASA/Europa Multiple Flyby Mission, ESA/JUICE). Detailed studies on the spectral behavior of hydrated minerals (silicates, sulfates) at cryogenic temperatures have implications in the correct interpretation of spectral data of Mars as well as of the icy Galilean satellites. Laboratory characterization is helpful in the possible identification and discrimination of this type of minerals, whose spectral features are considerably influenced by temperature variations, on surfaces of rocky planetary bodies; the presence of hydrated sulfates has important 
implications on the understanding of the geologic processes that occurred on such Solar System bodies. The presence of mono- and poly-hydrated sulfates on other Solar System bodies would be strictly related to geologic processes that have occurred in presence of liquid water, such as evaporation from standing water-bodies (e.g. lakes), sedimentation, or weathering of primary minerals, with potential subsequent astrobiological implications.

\section{Acknowledgements}

The hydrated minerals and set of measurements described in this work are part of the research project: "Key laboratory measurements for Solar System ices" (PI: Dr. Federico Tosi), funded in 2013 by INAF-IAPS in the framework of an internal call for original research projects not otherwise funded. ASI funded and supported measurements campaign. Funding and support from the Centre National d'Etude Spatiale and the Programme National de Planétologie are acknowledged.

\section{References}

Beck P., Schmitt B., Cloutis E.A., Vernazza P.: Low-temperature reflectance spectra of brucite and the primitive surface of 1-Ceres?, Icarus 257, 471-476, 2015

Bibring J-P., A. Soufflot, M. Berthé, Y. Langevin, B. Gondet, P. Drossart, M. Bouyé, M. Combes, P. Puget, A. Semery, G. Bellucci, V. Formisano, V. Moroz, V. Kottsov and the OMEGA Co-I team, OMEGA: Observatoire pour la Minéralogie, l'Eau, les Glaces et l'Activité, in Mars Express: the scientific payload. Ed. by Andrew Wilson, scientific coordination: Agustin Chicarro, ESA Publications Division, ISBN 92-9092-556-6, p. 37 - 49, 2004

Bonnefoy N. Développement d'un spectrophoto-goniomètre pour l'étude de la réflectance bidirectionnelle des surfaces géophysiques. Application au soufre et perspectives pour le satellite 1o. PhD thesis, Université Joseph Fourier, Grenoble, 2001

Brearley A.J. and Jones R.H.: Chondritic Meteorites, in: Papike, J.J. (Ed.), Planetary Materials. In: Reviews in Mineralogy, vol. 36. Mineralogical So- ciety of America, Washington, DC. Chap. 3

Brissaud O., Schmitt B., Bonnefoy N., Douté S., Rabou P., Grundy W., and Fily M.: Spectrogonio radiometer for the study of the bidirectional reflectance and polarization functions of planetary surfaces. 1. Design and tests, Applied Optics, Vol.43, Issue 9, pp. 1926-1937, http://dx.doi.org/10.1364/AO.43.001926, 2004 
Brueckner J.: Determination of chemical composition of soils and rocks at the MER landing sites Gusev crater and Meridiani Planum using the APXS, American Geophysical Union, Spring Meeting 2004, abstract \#V11A05

Burgess R., Wright I.P., Pilliinger C.T.: Determination of Sulphur-bearing components in C1 and C2 carbonaceous chondrites by stepped combustion, Meteoritics, 26, 55-64, 1991

Carlson R.W., Calvin W.M., Dalton J.B., Hansen G.B., Hudson R.L., Johnson R.E., McCord T.B., Moore M.H.: Europa's surface composition, Europa, Edited by Robert T. Pappalardo, William B. McKinnon, Krishan K. Khurana, University of Arizona Press, Tucson. The University of Arizona space science series ISBN: 9780816528448, p.283, 2009

Chevrier V. and Mathè P.E.: Mineralogy and evolution of the surface of Mars: A review, Planetary and Space Science, 55, 289-314, 2007

Chou I-M. and Seal II R.R.: Magnesium and calcium sulfate stabilities and the water budget of Mars, Journal Of Geophysical Research, VOL. 112, E11004, doi:10.1029/2007JE002898, 2007

Clark R.N. and Roush T.L.: Reflectance Spectroscopy: Quantitative Analysis Techniques for Remote Sensing Applications, Journal of Geophysical Research, VOL. 89, NO. B7, PAGES 6329-6340, 1984

Clark R.N., King T.V.V., Klejwa M., Swayze G.: High spectral resolution reflectance spectroscopy of minerals, Journal of Geophysical Research, Vol.95, No.B8, pp.12653-12680, 1990

Clark, R. N., Chapter 1: Spectroscopy of Rocks and Minerals, and Principles of Spectroscopy, in Manual of Remote Sensing, Volume 3, Remote Sensing for the Earth Sciences, (A.N. Rencz, ed.) John Wiley and Sons, New York, p 3- 58, 1999

Cloutis E.A., Hawthorne F.C., Mertzman S.A., Krenn K., Craig M.A., Marcino D., Methot M., Strong J., Mustard J.F., Blaney D.L., Bell III J.F., and Vilas F.: Detection and discrimination of sulfate minerals using reflectance spectroscopy, Icarus 184, 121-157, 2006

Cloutis E.A., Craig M.A., Mustard J.F., Kruzelecky R.V., Jamroz W.R., Scott A., Bish D.L., Poulet F., Bibring J-P., and King P.L.: Stability of hydrated minerals on Mars, Geophysical Research Letters, vol.34, L20202, doi:10.1029/2007GL031267, 2007

Craig M., Cloutis E.A., Kaletzke L., McCormack K., and Stewart L.: Alteration Of Hydration Absorption Features In Reflectance Spectra Of Selected Sulfates In A Low Pressure Environment: 0.45-4.3 um, Lunar and Planetary Science XXXVII, abstract n.2112, 2006

Crowley J.K.: Visible and Near-Infrared (0.4-2.5 $\mu \mathrm{m})$ Reflectance Spectra of Playa Evaporite Minerals, Journal Of Geophysical Research, VOL. 96, NO. B10, PAGES 16,231-16,240, 1991

Dalton III J.B., Prieto-Ballesteros O., Kargel J.S., Jamieson C.S., Jolivet J., Quinn R.: Spectral comparison of heavily hydrated salts with disrupted terrains on Europa, Icarus 177, 472-490, 2005 
Dalton III J.B.: Linear mixture modeling of Europa's non-ice material based on cryogenic laboratory spectroscopy, Geophysical Research Letters, VOL. 34, L21205, doi:10.1029/2007GL031497, 2007

Dalton III J.B., Pitman K.M., Jamieson C.S., Dobrea N.: Spectral properties of Hydrated Sulfate Minerals on Mars, EPSC Abstracts, Vol.6, EPSC-DPS2011-650, EPSC-DPS Joint Meeting, 2011

Dalton III J.B. and Pitman K.M.: Low temperature optical constants of some hydrated sulfates relevant to planetary surfaces, Journal Of Geophysical Research, VOL. 117, E09001, doi:10.1029/2011JE004036, 2012

Ehlmann B.L. and Edwards C.S.: Mineralogy of the Martian Surface, Annual Reviews Earth Planetary Science, 42, 291-315, 2014

Feldman W.C., Mellon M.T., Maurice S., Prettyman T.H., Carey J.W., Vaniman D.T., Bish D.L., Fialips C.I., Chipera S.J., Kargel J.S., Elphic R.C., Funsten H.O., Lawrence D.J., and Tokar R.L.: Hydrated States of MgSO4 at equatorial latitudes on Mars, Geophysical Research Letters, vol.31, L16702, doi:10.1029/2004GL020181, 2004

Fredriksson K. and Kerridge J.F.: Carbonates and Sulfates in Cl Chondrites: Formation by Aqueous Activity on the Parent Body, Meteoritics, 23, pp.35-44, 1988

Gendrin A., Mangold N., Bibring J-P., Langevin Y., Gondet B., Poulet F., Bonello G., Quantin C., Mustard J., Arvidson R., LeMouèlic S.: Sulfates in Martian Layered Terrains: the OMEGA/Mars Express View, Science, Vol. 307, p.1587-1590, 2005

Gounelle, M. and Zolensky, M.E.: A terrestrial origin for sulfates veins in Cl1 chondrites, Meteoritics and Planetary Science, 36, 1321-1329, 2001

Grisolle F. Les condensats saisonniers de Mars : étude expérimentale de la formation et du métamorphisme de glaces de $\mathrm{CO}_{2}$. PhD thesis, Université Joseph Fourier, Grenoble, 2013

Grisolle F., Schmitt B., Beck P., Philippe S., and Brissaud O.: Experimental simulation of the condensation and metamorphism of seasonal $\mathrm{CO}_{2}$ condensates under martian conditions, European Planetary Science Congress, EPSC Abstracts Vol. 9, EPSC2014-635-1, 2014

Hunt G.R.: Spectral Signatures of Particulate Minerals in the Visible and Near Infrared, Geophysics, vol.42, n.3, pp.501-513, 1977

Hutchison R.: Meteorites, a petrologic, chemical and isotopic Synthesis, Cambridge University Press, Cambridge, UK, ISBN 052147010 2, 2006

Jamieson C.S., Dobrea N., Dalton III J.B., Pitman K.M., and Abbey W.J.: Grain size and temperature effects on the interpretation of remote sensing spectra, Asteroids, Comets, Meteors, ACM conference, abstract n.6384, 2012 
661 Langevin Y., Piccioni G., Eng P., Filacchione G., Poulet F. and the MAJIS team: THE MAJIS VIS-NIR 662 IMAGING SPECTROMETER FOR THE JUICE MISSION, $45^{\text {th }}$ Lunar and Planetary Science Conference, 663 LPSC abstract n.2493, 2014

664 McCord T.B., Hansen G.B., Fanale F.P., Carlson R.W., Matson D.L., Johnson T.V., Smythe W.D., 665 Crowley J.K:, Martin P.D., Ocampo A., Hibbitts C.A., Granahan J.C., the NIMS Team: Salts on 666 Europa's Surface Detected by Galileo's Near Infrared Mapping Spectrometer, SCIENCE, VOL. 280, 667 1242-1245, DOI: 10.1126/science.280.5367.1242, 1998

668 McCord T.B., Hansen G.B., Matson D.L., Johnson T.V., Crowley J.K., Fanale F.P., Carlson R.W., 669 Smythe W.D., Martin P.D., Hibbitts C.A., Granahan J.C., and Ocampo A.: Hydrated salt minerals on 670 Europa's Surface from the Galileo near-infrared mapping spectrometer (NIMS) investigation, 671 Journal of Geophysical Research, vol.104, No. E5, 11,827-11,851, 1999

672 McCord, T.B., Hansen, G.B., Hibbitts, C.A., 2001. Hydrated salt minerals on Ganymede's surface: 673 Evidence of an ocean below. Science 292, 1523-1525.

674 McCord T.B., Hansen G.B., Combe J-P., Hayne P.: Hydrated minerals on Europa's surface: An 675 improved look from the Galileo NIMS investigation, Icarus, 209, 639-650, 676 doi:10.1016/j.icarus.2010.05.026, 2010

677 Murchie S.L., and CRISM team: Compact Reconnaissance Imaging Spectrometer for Mars (CRISM) 678 on Mars Reconnaissance Orbiter (MRO), Journal Of Geophysical Research, VOL. 112, E05S03, 679 doi:10.1029/2006JE002682, 2007

680 Murchie S.L., Mustard J.F., Ehlmann B.L., Milliken R.E., Bishop J.L., McKeown N.K., Noe Dobrea E.Z., 681 Seelos F.P., Buczkowski D.L., Wiseman S.M., Arvidson R.E., Wray J.J., Swayze G., Clark R.N., Des 682 Marais D.J., McEwen A.S. and Bibring J-P.: A synthesis of Martian aqueous mineralogy after 1 Mars 683 year of observations from the Mars Reconnaissance Orbiter, Journal Of Geophysical Research, VOL. 684 114, EOOD06, doi:10.1029/2009JE003342, 2009

685

686

687

688

689

690

691

692

693

694

695

696

Nachon, M., Mangold, N., Clegg, S., Schröder, S., Forni, O., S, Gasnault, O., Lasue, J., Le Mouélic, S., Lewin, E., Maurice, S., Newsom, H., Wiens, R., Fabre C., Dromart G., Leveillé, R., Bridges, J., Ehlmann, B., Grotzinger, J., Dyar, D. and the MSL team: Sulfate calcium veins observed by the ChemCam instrument onboard Curiosity, European Planetary Science Congress, EPSC Abstracts Vol. 8, EPSC2013-534, 2013

Nathues A., M. Hoffmann, M. Schaefer, L. Le Corre, V. Reddy, T. Platz, E. A. Cloutis, U. Christensen, T. Kneissl, J.-Y. Li, K. Mengel, N. Schmedemann, T. Schaefer, C. T. Russell, D. M. Applin, D. L. Buczkowski, M. R. M. Izawa, H. U. Keller, D. P. O’Brien, C. M. Pieters, C. A. Raymond, J. Ripken, P. M. Schenk, B. E. Schmidt, H. Sierks1, M. V. Sykes, G. S. Thangjam \& J.-B. Vincent: Sublimation in bright spots on (1) Ceres, Nature Letter, vol.528, pp.237-240, doi:10.1038/nature15754, 2015

Rice M.S., J.F. Bell III, A. Godber, D. Wellington, A.A. Fraeman, J.R. Johnson, K.M. Kinch, M.C. Malin, J.P. Grotzinger, and the MSL Science Team: Mastcam multispectral imaging results from the Mars 
697

Science Laboratory investigation in Yellowknife Bay, European Planetary Science Congress, EPSC Abstracts Vol. 8, EPSC2013-762, 2013

Piccioni G., Langevin Y., Filacchione G., Poulet F., Tosi F., Eng P., Dumesnil C., Zambelli M., Saggin B., Fonti S., Grassi D. and F. Altieri F.: MAJIS, the Moons And Jupiter Imaging Spectrometer, designed for the future ESA/JUICE mission, Geophysical Research Abstracts Vol. 16, EGU201410925-2, EGU General Assembly 2014

Roach L.H., Mustard J.F., Murchie S.L., Bibring J-P., Forget F., Lewis K.W., Aharonson O., Vincendon M., and Bishop J.L.: Testing evidence of recent hydration state change in sulfates on Mars, Journal Of Geophysical Research, VOL. 114, E00D02, doi:10.1029/2008JE003245, 2009

Vaniman D.T., Bish D.L., Chipera S.J., Fialips C.I., Carey J.W. and Feldman W.C.: Magnesium sulphate salts and the history of water on Mars, Nature, vol.431, 663-665, doi:10.1038/nature/02973, 2004

Van Keulen L.M., McCord T.B., Hansen G.B., Hibbitts C.A., and Crowley J.K.: The Effect Of Grain Size On The Near-Infrared Reflectance Spectra Of Some Hydrated Salt Minerals, Lunar and Planetary Science XXXI, abstract n.1539, 2000

Wang A., Freeman J.F., Jolliff B.L., and Arvidson R.E.: Conversion Of Crystalline $\mathrm{MgSO}_{4} . \mathrm{XH}_{2} \mathrm{O}$ To The Hydrated Amorphous Phase - A Raman, NIR, and XRD Study, Lunar and Planetary Science XXXVII, abstract n.2168, 2006

Warren J.K.: Evaporites: Sediments, Resources and Hydrocarbons, Springer-Verlag, Berlin Heidelberg, 2006

Warren J.K.: Evaporites through time: Tectonic, climatic and eustatic controls in marine and nonmarine deposits, Earth-Science Reviews 98, 217-268, 2010

Weitz C.M., Noe Dobrea E., and Wray J.J.: Mixtures of clays and sulfates within deposits in western Melas Chasma, Mars, Icarus, 251, 291-314, 2015

Wray J.J., Milliken R., Swayze G.A., Ehlmann B.L., Dundas C.M., Baldridge A.M., Andrews-Hanna J.C., and Murchie S.L.: Evaporites in Martian Paleolakes: Observations and Implications, American Geophysical Union, Fall Meeting 2009, abstract \#P41B06 